\title{
Functional Organization of Cutaneous and Muscle Afferent Synapses onto Immature Spinal Lamina I Projection Neurons
}

\author{
Jie Li and $\oplus^{-M a r k ~ L . ~ B a c c e i ~}$ \\ Pain Research Center, Department of Anesthesiology, University of Cincinnati Medical Center, Cincinnati, Ohio 45267
}

It is well established that sensory afferents innervating muscle are more effective at inducing hyperexcitability within spinal cord circuits compared with skin afferents, which likely contributes to the higher prevalence of chronic musculoskeletal pain compared with pain of cutaneous origin. However, the mechanisms underlying these differences in central nociceptive signaling remain incompletely understood, as nothing is known about how superficial dorsal horn neurons process sensory input from muscle versus skin at the synaptic level. Using a novel ex vivo spinal cord preparation, here we identify the functional organization of muscle and cutaneous afferent synapses onto immature rat lamina I spino-parabrachial neurons, which serve as a major source of nociceptive transmission to the brain. Stimulation of the gastrocnemius nerve and sural nerve revealed significant convergence of muscle and cutaneous afferent synaptic input onto individual projection neurons. Muscle afferents displayed a higher probability of glutamate release, although short-term synaptic plasticity was similar between the groups. Importantly, muscle afferent synapses exhibited greater relative expression of $\mathrm{Ca}^{2+}$-permeable AMPARs compared with cutaneous inputs. In addition, the prevalence and magnitude of spike timing-dependent long-term potentiation were significantly higher at muscle afferent synapses, where it required $\mathrm{Ca}^{2+}$-permeable AMPAR activation. Collectively, these results provide the first evidence for afferent-specific properties of glutamatergic transmission within the superficial dorsal horn. A larger propensity for activity-dependent strengthening at muscle afferent synapses onto developing spinal projection neurons could contribute to the enhanced ability of these sensory inputs to sensitize central nociceptive networks and thereby evoke persistent pain in children following injury.

Key words: dorsal horn; glutamate; pain; patch clamp; primary afferent; synaptic plasticity

\section{Significance Statement}

The neurobiological mechanisms underlying the high prevalence of chronic musculoskeletal pain remain poorly understood, in part because little is known about why sensory neurons innervating muscle appear more capable of sensitizing nociceptive pathways in the CNS compared with skin afferents. The present study identifies, for the first time, the functional properties of muscle and cutaneous afferent synapses onto immature lamina I projection neurons, which convey nociceptive information to the brain. Despite many similarities, an enhanced relative expression of $\mathrm{Ca}^{2+}$-permeable AMPA receptors at muscle afferent synapses drives greater LTP following repetitive stimulation. A preferential ability of the dorsal horn synaptic network to amplify nociceptive input arising from muscle is predicted to favor the generation of musculoskeletal pain following injury.

\section{Introduction}

Chronic and recurrent pain is highly prevalent in children and adolescents (Perquin et al., 2000; Stanford et al., 2008). In addi-

\footnotetext{
Received 0ct. 12, 2016; revised Dec. 13, 2016; accepted Dec. 24, 2016.

Author contributions: J.L. and M.L.B. designed research; J.L. performed research; J.L. and M.L.B. analyzed data;

J.L. and M.L.B. wrote the paper.

This work was supported by National Institutes of Health Grants NS080889 and NS072202 to M.L.B. We thank Elizabeth Serafin for technical support on the project.

The authors declare no competing financial interests.

Correspondence should be addressed to Dr. Mark L. Baccei, Pain Research Center, Department of Anesthesiology,

University of Cincinnati Medical Center, 231 Albert Sabin Way, Cincinnati, OH 45267. E-mail: mark.baccei@uc.edu.
}

tion to the intensely unpleasant sensory and emotional experience, pediatric pain interferes with normal social and cognitive development (Hunfeld et al., 2001; Merlijn et al., 2003) and lowers the overall quality of life for children and their families (Jastrowski Mano et al., 2011; Öztop et al., 2016; Rabbitts et al., 2016). While headache has been identified as the most prevalent type of pain experienced during childhood, musculoskeletal pain also commonly occurs across the pediatric population (King et al., 
2011). Overall, it is clear that persistent pain requiring clinical management predominantly originates from deep tissues, such as muscle, rather than cutaneous regions. For example, while peripheral nerve injury frequently causes chronic neuropathic pain (Jensen and Finnerup, 2014), selective damage to the sural nerve (innervating skin) often fails to do so (Miloro and Stoner, 2005; IJpma et al., 2006).

Repetitive activation of nociceptive primary afferents leads to an activity-dependent increase in the excitability of neuronal circuits in the CNS, termed central sensitization, that contributes to chronic pain (Latremoliere and Woolf, 2009; Woolf, 2011). However, sensory neurons are not homogeneous in their ability to evoke central sensitization, as muscle afferents are reportedly more effective at increasing the excitability of spinal flexion reflexes than cutaneous afferents (Wall and Woolf, 1984; McMahon and Wall, 1989). In addition, repetitive stimulation of the gastrocnemius nerve (GS; innervating muscle) evokes greater LTP of C fiber-evoked field potentials in the spinal dorsal horn compared with sural nerve stimulation (Zhou et al., 2010; Zhang et al., 2016). Given that LTP represents a means by which the gain of nociceptive signaling can be rapidly amplified (Ikeda et al., 2006; Sandkuhler and Gruber-Schoffnegger, 2012), these results are consistent with the notion that the robust activation of muscle afferents is more likely to sensitize central nociceptive networks and drive persistent pain.

The mechanistic basis for this relationship between primary afferent subtype and the ability to evoke central sensitization remains poorly understood, in part because little is known about the degree to which central nociceptive networks process muscle and cutaneous sensory input differently. Anatomical studies suggest that muscle and cutaneous nerves exhibit distinct projection patterns in the spinal dorsal horn (McMahon and Wall, 1985; Mense and Craig, 1988; Panneton et al., 2005). Therefore, the targeting of discrete subpopulations of dorsal horn neurons by cutaneous and muscle afferents, or differences in the rostrocaudal extent of these central projections, could contribute to the greater propensity of muscle afferents to drive hyperexcitability in spinal nociceptive networks. However, an alternative possibility is that fundamental differences exist in the functional organization of muscle versus cutaneous afferent synapses onto dorsal horn neurons. Unfortunately, nothing is known about whether the phenotype of primary afferent synapses onto second-order neurons in the pain pathway depends upon their peripheral target.

Using a novel ex vivo spinal cord preparation, which permits patch-clamp recording from ascending projection neurons in response to the selective stimulation of muscle or cutaneous inputs, the present study provides the first evidence for afferent-specific glutamatergic transmission within central nociceptive circuits. Most strikingly, muscle afferent synapses showed a significantly greater susceptibility to LTP following repetitive activation, which likely reflects a higher postsynaptic expression of $\mathrm{Ca}^{2+}$-permeable AMPA receptors compared with cutaneous inputs to the same neuronal population during early life. These differences in synaptic organization could result in a preferential amplification of muscle sensory input by the dorsal horn network following tissue or nerve injury, leading to increased nociceptive signaling to the brain and the subsequent generation of pain hypersensitivity.

\section{Materials and Methods}

All experiments adhered to animal welfare guidelines established by the University of Cincinnati Institutional Animal Care and Use Committee.

Retrograde labeling of spinal projection neurons. Sprague Dawley rat pups of either sex were anesthetized with a mixture of ketamine
(90 mg/kg) and xylazine (10 mg/kg) on postnatal day 0 (P0) to P1 and placed in a plaster body mold that was secured in a stereotaxic apparatus (World Precision Instruments) as described previously (Hoorneman, 1985). The scalp was incised, and a small hole was made in the skull using an OmniDrill35 (World Precision Instruments). The pup received a single injection ( $50-100 \mathrm{nl})$ of FAST DiI oil $(2.5 \mathrm{mg} / \mathrm{ml}$; Invitrogen $)$ into the parabrachial nucleus (PB) using a Hamilton microsyringe (62RN; $2.5 \mu \mathrm{l}$ volume) equipped with a 28 gauge needle. The following stereotaxic coordinates were used (relative to $\lambda$ ): $2.7 \mathrm{~mm}$ caudal, $1.0 \mathrm{~mm}$ lateral, and $3.3 \mathrm{~mm}$ ventral. The skin was closed with Vetbond and the pups returned to the home cage before the beginning of the electrophysiological experiments.

Intact spinal cord-DRG-peripheral nerve preparation. At P7-P11, pups were terminally anesthetized with sodium pentobarbital (Fatal-Plus; Vortec Pharmaceuticals), transcardially perfused with oxygenated aCSF (composition in mM as follows: $125 \mathrm{NaCl}, 2.5 \mathrm{KCl}, 25 \mathrm{NaHCO}_{3}, 1.0$ $\mathrm{NaH}_{2} \mathrm{PO}_{4}, 1.0 \mathrm{MgCl}_{2}, 2.0 \mathrm{CaCl}_{2}$, and 25 glucose, $\mathrm{pH}$ 7.2) and decapitated. The spinal cord, L4/L5 DRGs and associated peripheral nerves, including the GS, tibial, peroneal, and sural nerves (Fig. 1A), were removed and immersed in oxygenated aCSF, and the dura and pia mater were carefully stripped from the dorsal surface of the spinal cord. The preparation was then placed in a submersion-type recording chamber (RC-22; Warner Instruments), mounted on the stage of an upright microscope (BX51WI; Olympus) and perfused at room temperature with oxygenated aCSF at a rate of $1.5-3 \mathrm{ml} / \mathrm{min}$. Lamina I neurons were visualized within the intact spinal cord using infrared LED illumination as described previously (Safronov et al., 2007; Szucs et al., 2009). Spinoparabrachial (spino-PB) projection neurons were subsequently identified via DiI labeling and classified based on morphology as fusiform, pyramidal, or multipolar (Fig. 1C,D).

Patch-clamp recordings. Patch electrodes were constructed from thinwalled single-filamented borosilicate glass $(1.5 \mathrm{~mm}$ outer diameter; World Precision Instruments) using a microelectrode puller (P-97; Sutter Instruments). Pipette resistances ranged from 4 to $6 \mathrm{~m} \Omega$, and seal resistances were $>1 \mathrm{G} \Omega$. For the majority of experiments, patch electrodes were filled with a solution containing the following (in $\mathrm{mm}$ as follows): 130 Cs-gluconate, $10 \mathrm{CsCl}, 10 \mathrm{HEPES}, 11 \mathrm{EGTA}, 1.0 \mathrm{CaCl}_{2}$, and 2.0 MgATP, pH 7.2 (295-300 mOsm) to improve space clamp and allow for improved voltage clamping of projection neurons at depolarized holding potentials during the recording of IPSCs $\left(V_{\text {hold }}=0 \mathrm{mV}\right)$ and NMDAR-mediated EPSCs $\left(\mathrm{V}_{\text {hold }}=50 \mathrm{mV}\right)$. For current-clamp experiments and studies of spike timing-dependent plasticity (STDP), the intracellular solution consisted of the following (in mM): $130 \mathrm{~K}$-gluconate, $10 \mathrm{KCl}, 10 \mathrm{HEPES}, 10 \mathrm{Na}$-phosphocreatine, $4 \mathrm{MgATP}$, and $0.3 \mathrm{Na}_{2}$-GTP, pH 7.2 (295-300 mOsm).

Patch-clamp recordings were obtained from DiI-labeled neurons in lamina I using a Multiclamp 700B amplifier (Molecular Devices). AMPAR-mediated EPSCs were evoked from a holding potential of -70 $\mathrm{mV}$ by electrical stimulation of the $\mathrm{GS}$ or sural nerves $(0-1 \mathrm{~mA}, 0.1-5 \mathrm{~ms}$ duration) delivered via a suction electrode connected to a constantcurrent stimulator (Master-8). In some studies, GS and sural inputs to a single projection neuron were alternately stimulated to examine the degree of synaptic convergence, and the order of sural versus GS stimulation was randomized across experiments. EPSCs mediated by lowthreshold A-fibers were classified as monosynaptic based on their ability to follow repetitive stimulation $(5-10 \mathrm{~Hz})$ with a constant latency (variation $\leq 2 \mathrm{~ms}$ ) and an absence of synaptic failures. Meanwhile, highthreshold A-fiber- and C-fiber-mediated EPSCs were classified as monosynaptic if no failures were observed during 2 and $1 \mathrm{~Hz}$ stimulation, respectively (Torsney and MacDermott, 2006). Although primary afferent conduction velocity $(\mathrm{CV})$ was not routinely measured in the present study, the average peripheral nerve-dorsal root length ( $\sim 32 \mathrm{~mm}$ for both sural and GS nerve preparations) and the range of onset latencies observed for monosynaptic EPSCs allowed for the calculation of an estimated range of CVs for the afferents sampled in our experiments. Notably, these measurements significantly underestimate CV for a number of reasons as discussed previously (Li et al., 2015). Polysynaptic IPSCs were recorded from a holding potential of $0 \mathrm{mV}$ following stimulation of the GS and/or sural nerves. To calculate the ratio of primary afferent- 


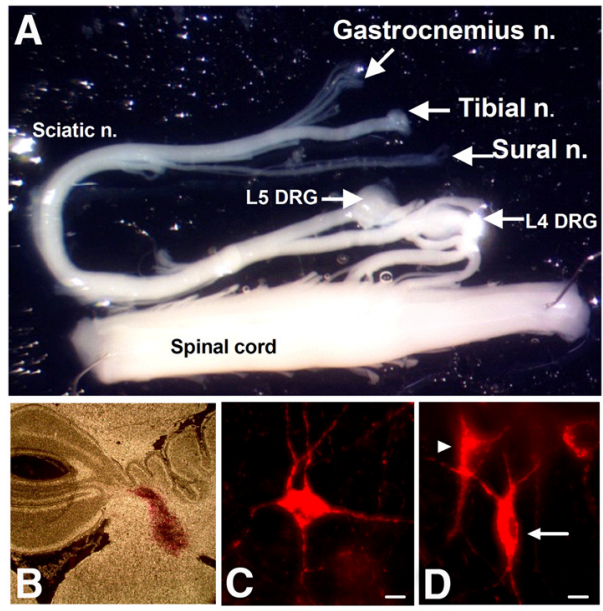

E

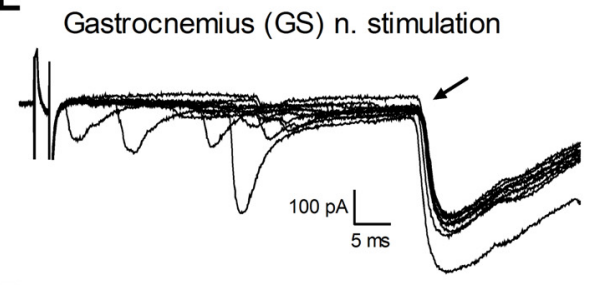

$\mathbf{F}$

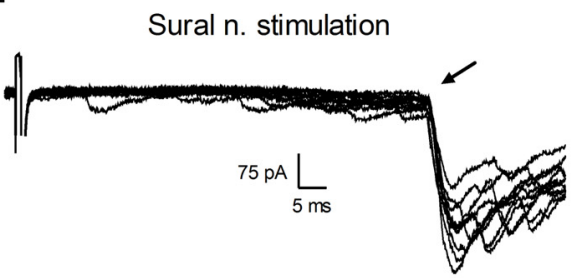

G

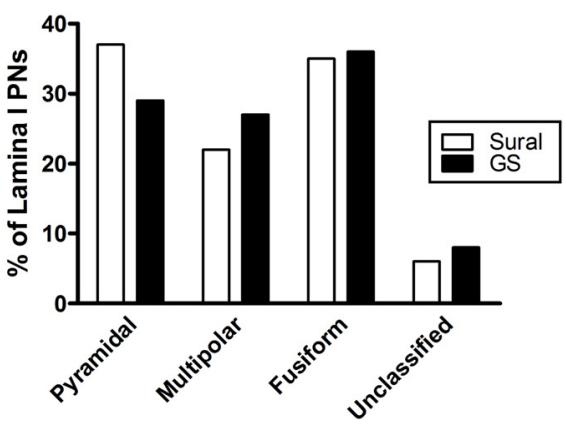

Figure 1. Cutaneous and muscle afferent synapses onto identified morphological subtypes of lamina I projection neurons. $A$, Image of an ex vivo intact spinal cord preparation isolated from a rat at $P 7$, which includes the $L 4$ and $L 5 D R G s$, sciatic nerve, and associated peripheral nerves. The common peroneal nerve has been removed in the illustrated preparation. $\boldsymbol{B}$, Representative image showing the Dil injection site within the PB. C, Example of a multipolar lamina I projection neuron that was visible within the intact spinal cord $3 \mathrm{~d}$ after the injection of Dil into the rat PB at birth. Scale bar, $10 \mu \mathrm{m}$. D, Projection neurons exhibiting pyramidal (arrowhead) and fusiform (arrow) morphology were also clearly evident within lamina I of the intact spinal cord. Scale bar, $10 \mu \mathrm{m} . \boldsymbol{E}, \boldsymbol{F}$, Electrical stimulation of the attached GS nerve innervating muscle $(\boldsymbol{E})$, or the sural nerve containing cutaneous afferents $(\boldsymbol{F})$, evoked EPSCs within identified projection neurons (arrows). G, There were no significant differences in the morphological subtypes of lamina I projection neurons that received synaptic input from sural $(n=105)$ versus $G S$ $(n=104)$ afferents $\left(p=0.581 ; \chi^{2}\right.$ test $)$ during early life.

evoked excitation versus inhibition (i.e., $\mathrm{E} / \mathrm{I}$ ratio) in neonatal projection neurons, AMPAR-mediated EPSCs were evoked in response to GS (or sural) nerve stimulation across a range of intensities. After recording the total EPSCs (i.e., including both monosynaptic and polysynaptic inputs), projection neurons were then voltage-clamped at $0 \mathrm{mV}$ and IPSCs recorded in response to GS (or sural) stimulation across the same range of stimulus intensities used for evoking EPSCs. At each stimulus intensity, the area under the total evoked EPSC and IPSC (i.e., AUC) was averaged across 5 trials and the E/I ratio calculated as follows: mean AUC of EPSC/ mean AUC of IPSC. In separate experiments, current-clamp recordings of nerve-evoked action potential discharge were obtained at the resting membrane potential of the sampled neuron. In all experiments investigating convergent cutaneous and muscle sensory input to individual projection neurons, the order of nerve stimulation (i.e., GS vs sural stimulation) was randomized across recordings.

To investigate the degree to which cutaneous and muscle afferent synapses onto immature projection neurons exhibit different probabilities of glutamate release, monosynaptic EPSCs were evoked by pairs of identical stimuli $(1.2 \times$ threshold at a frequency of $0.067 \mathrm{~Hz})$ delivered at various interstimulus intervals $(75-500 \mathrm{~ms} ; 10$ trials each), and the paired-pulse ratio (PPR) was calculated as follows: $\mathrm{PPR}=$ mean amplitude of EPSC2/mean amplitude of EPSC1. To examine the extent of short-term depression (STD) at these synapses, monosynaptic EPSCs were evoked by a train of 40 stimuli (delivered at 1,2, 5, or $10 \mathrm{~Hz}$ ) and a mean plateau amplitude was calculated as follows: $y / x$, where $y$ is the mean amplitude of the final 5 EPSCs and $x$ is the mean amplitude of the first EPSC across all trials in a given neuron. Recovery from STD was investigated via the application of a train of 40 stimuli $($ at $10 \mathrm{~Hz})$ followed at various intervals $(0.2-10 \mathrm{~s})$ by a single test stimulus of the same intensity. The degree of recovery was calculated as $(z-y) /(x-y)$, where $z$ is the amplitude of the response to the test stimulus and $x$ and $y$ are as described above.

To explore possible afferent-specific properties of long-term synaptic plasticity, we used a recently described protocol for the induction of spike timing-dependent LTP ( $\mathrm{t}$-LTP) in ascending spinal projection neurons (Li and Baccei, 2016). Briefly, monosynaptic EPSCs were evoked from a holding potential of $-70 \mathrm{mV}$ by stimulation of the attached GS or sural nerve (every $15 \mathrm{~s}$ at an intensity of $1-1.2 \times$ threshold). To evoke t-LTP, following the verification of a stable baseline EPSC amplitude for $\geq 5$ min, the same primary afferent stimulus was paired with a postsynaptic action potential evoked by direct intracellular current injection (300$800 \mathrm{pA} ; 5 \mathrm{~ms})$ at an interval of $10-50 \mathrm{~ms}$ after the arrival of the presynaptic input (i.e., $\Delta t=-10 \mathrm{~ms}, \Delta t=-20 \mathrm{~ms}$, or $\Delta t=-50 \mathrm{~ms}$ ) under current-clamp conditions. After administration of the pairing protocol (30 pairs of stimuli at $0.2 \mathrm{~Hz}$ ), projection neurons were again voltageclamped at $-70 \mathrm{mV}$ and the nerve-evoked EPSCs recorded for $\geq 25 \mathrm{~min}$ to calculate a mean normalized change in EPSC amplitude (\% baseline). Previous control experiments showed that the administration of the presynaptic or postsynaptic stimulation alone (i.e., no pairing) failed to alter synaptic efficacy at sensory synapses onto lamina I projection neurons (Li and Baccei, 2016).

To examine the relative contribution of NMDARs containing the NR2B subunit to the overall NMDAR response, NMDAR-mediated currents were isolated at a holding potential of $50 \mathrm{mV}$ in the presence of $10 \mu \mathrm{M}$ NBQX, $10 \mu \mathrm{m}$ gabazine, and $0.5 \mu \mathrm{M}$ strychnine (to block AMPARs, $\mathrm{GABA}_{\mathrm{A}} \mathrm{Rs}$, and glycine receptors, respectively). The kinetics of NMDAR current decay were compared between groups by fitting the total NMDAR current (averaged from 5 consecutive EPSCs) with a double exponential function (Clampfit 10.3, Molecular Devices). The degree to which the mean amplitude of the NMDAR current was inhibited by the bath application of the NR2B-selective NMDAR antagonist Ro 25-6981 maleate $(5 \mu \mathrm{M})$ was measured and compared between the GS and sural inputs. Although the observed NMDAR currents may include activity occurring at "silent" (i.e., pure NMDAR) synapses, which have been documented in the immature spinal dorsal horn (Bardoni et al., 1998; Li and Zhuo, 1998; Baba et al., 2000), the relative contribution of silent synapses to the overall NMDAR currents at sural versus GS afferent synapses was not examined in the present study. The relative expression of $\mathrm{Ca}^{2+}$-permeable AMPARs at muscle and cutaneous afferent synapses was evaluated by measuring the fraction of monosynaptic EPSC amplitude (averaged from 5 consecutive EPSCs), which was blocked by bath application of the selective $\mathrm{Ca}^{2+}$-permeable AMPAR antagonist IEM $1460(10 \mu \mathrm{M})$. 
Membrane voltages were adjusted for liquid junction potentials $(\sim-14 \mathrm{mV})$ calculated using JPCalc software (P. Barry, University of New South Wales, Sydney, Australia; modified for Molecular Devices). Currents were filtered at $4-6 \mathrm{kHz}$ through a $-3 \mathrm{~dB}$, four-pole low-pass Bessel filter, digitally sampled at $20 \mathrm{kHz}$, and stored on a personal computer (ICT) using a commercially available data acquisition system (Digidata 1440A with pClamp 10.3 software; Molecular Devices).

Statistics. Data were analyzed using two-way ANOVA (with Bonferroni multiple-comparison test; Prism 5.0 software; GraphPad Software) unless specified otherwise. The effects of pharmacological antagonists on EPSC amplitude were compared between the GS and sural groups using the Mann-Whitney test. The distributions of GS and sural synaptic inputs as a function of projection neuron morphology were analyzed using the $\chi^{2}$ test, as were the patterns of long-term synaptic plasticity evoked at muscle and cutaneous afferent synapses. $n$ refers to the number of neurons sampled in a given group. Data are expressed as mean \pm SEM.

\section{Results}

\section{Convergence of cutaneous and muscle sensory input onto} immature spinal projection neurons

Both cutaneous and muscle sensory afferents have been reported to target lamina I of the rodent spinal cord (Panneton et al., 2005). However, the degree to which these central projections innervate distinct populations of ascending projection neurons remains unclear. To address this issue, whole-cell patch clamp recordings were obtained from immature spino- $\mathrm{PB}$ neurons in the intact rat spinal cord (Fig. $1 A$ ), which were identified via the retrograde transport of DiI injected into $\mathrm{PB}$ at $\mathrm{P} 0$ to $\mathrm{P} 1$ (Fig. $1 B$ ). Sampled lamina I neurons could be classified as pyramidal, multipolar, or fusiform based on their somatodendritic morphology (Fig. 1C,D), as described previously (Prescott and De Koninck, 2002). Electrical stimulation of the GS or sural nerve was used to activate primary afferents innervating muscle or skin, respectively, which evoked EPSCs in the projection neurons (Fig. $1 E, F)$. There was no statistically significant difference in the morphological subtypes of spino-PB neurons that received input from the GS ( $n=104$ projection neurons) or sural $(n=105)$ nerves $\left(p=0.581 ; \chi^{2}\right.$ test; Fig. $\left.1 G\right)$ during the early postnatal period.

To investigate the extent to which cutaneous and muscle afferent synapses may converge onto individual lamina I projection neurons, alternate stimulation was applied to both sural and GS inputs to single spino-PB neurons (Fig. 2A). Primary afferent-evoked EPSCs were classified as monosynaptic or polysynaptic based on their response to repetitive stimulation (see Materials and Methods). Monosynaptic EPSCs were mediated by afferents with estimated conduction velocities ranging from 2.25 to $0.39 \mathrm{~m} / \mathrm{s}$, suggesting that spino- $\mathrm{PB}$ neurons receive direct connections from both $\mathrm{A}$ - and $\mathrm{C}$-fiber afferents during the early postnatal period. As might be predicted from prior anatomical studies (Panneton et al., 2005), the relative balance of sural versus GS excitatory transmission onto projection neurons varied according to their mediolateral position in the superficial dorsal horn (SDH). Projection neurons in the lateral portion of the $\mathrm{SDH}(n=15)$ predominantly received cutaneous input (Fig. $2 B$ ), whereas projection neurons located medial to the dorsal root entry zone $(n=23)$ were characterized by significant glutamatergic input from muscle afferents (Fig. 2C). Nonetheless, a considerable percentage of immature spino-PB neurons received convergent excitatory input from the sural and GS nerves (Fig. $2 B, C$ ), regardless of whether they were located in the lateral $(\sim 47 \%$; 7 of 15 neurons) or medial ( $\sim 61 \%$; 14 of 23 ) dorsal horn. Strik-
A

GS

Sural
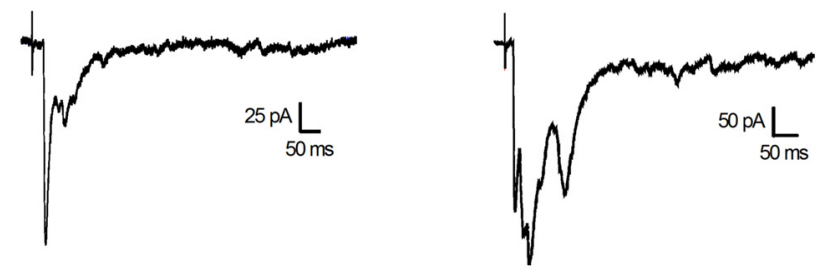

B
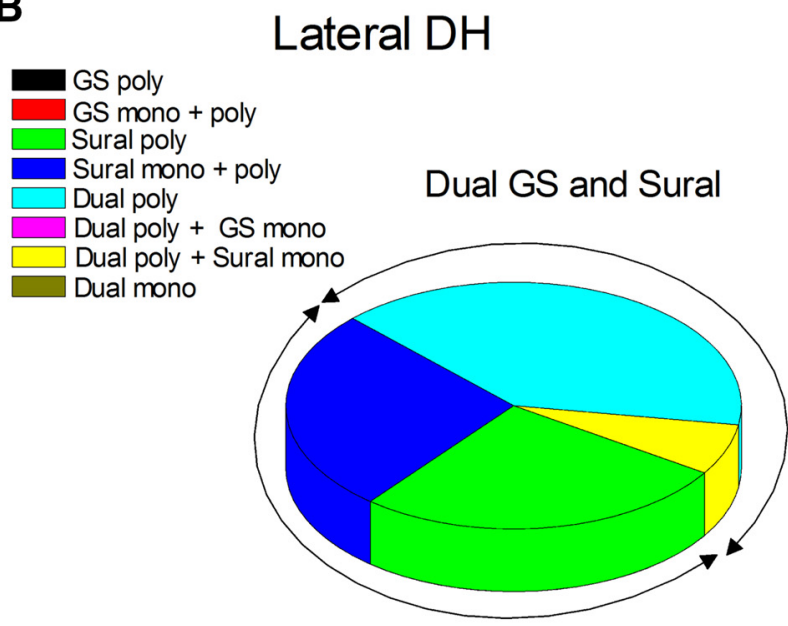

Sural only

C

\section{Medial DH}

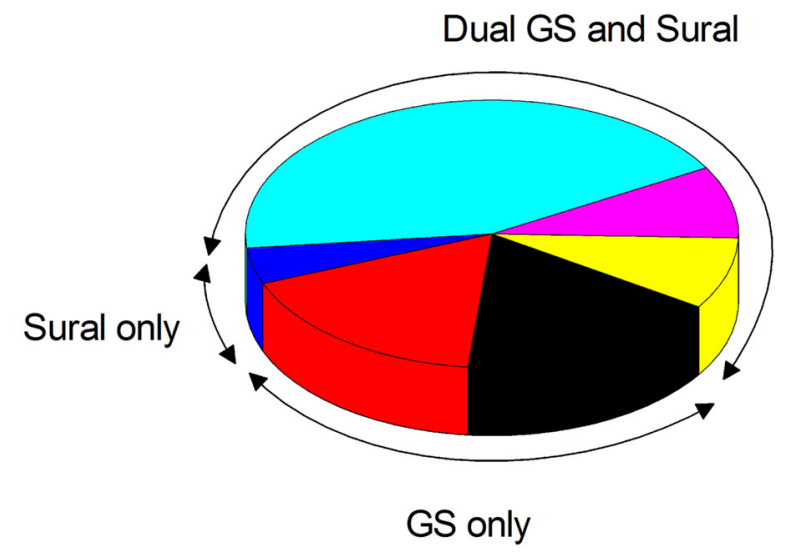

Figure 2. Convergence of cutaneous and muscle afferent synaptic input onto single lamina I projection neurons in the neonatal rat spinal cord. $A$, Representative example of the EPSCs recorded in an individual spino-PB neuron in response to the stimulation of the GS (left) or sural (right) nerve in the intact spinal cord preparation. $\boldsymbol{B}$, Distribution of monosynaptic and polysynaptic inputs to lamina I spino-PB neurons located lateral to the dorsal root entry zone, demonstrating a preponderance of sural nerve input in this region of the dorsal horn (DH) as well as a high proportion of projection neurons ( $~ 47 \% ; 7$ of 15$)$ that exhibited convergentinputfrom the sural and GSnerves. C, Themajority of immature spino-PBneurons residing in themedial portion of lamina I received synapticinput from afferents traveling in the GS nerve, with a significant fraction of those cells ( $\sim 61 \% ; 14$ of 23$)$ also receiving convergent input from cutaneous afferents from the sural nerve. Samelegend as $\operatorname{in} \boldsymbol{B}$.

ingly, this convergence was exclusively polysynaptic in nature, as we failed to observe lamina I projection neurons that received monosynaptic input from both the sural and GS nerves (Fig. $2 B, C$ ). 
Feedforward excitation and inhibition of projection neurons by muscle and cutaneous input to the spinal dorsal horn during early life

The identification of neonatal projection neurons that received convergent synaptic input from the sural and GS nerves provided a valuable opportunity to determine whether cutaneous and muscle afferents differ in their ability to evoke "feedforward" excitation versus inhibition onto the key output neurons of the spinal SDH network (Fig. $3 A, B$ ). Examining the ratio of primary afferent-evoked excitation to inhibition (E/I ratio; see Materials and Methods) across a range of stimulus intensities failed to reveal statistically significant differences between the stimulation of sural and GS nerves $\left(n=10 ; F_{(1,88)}=0.53 ; p=0.469\right.$; two-way ANOVA; Fig. $3 C$ ). Nonetheless, separate current-clamp recordings demonstrated that sural nerve stimulation was more effective at driving action potential firing in the sampled lamina I projection neurons compared with stimulation of afferents traveling in the GS nerve $\left(n=11 ; F_{(1,80)}=9.73 ; p=0.0025\right.$; repeatedmeasures two-way ANOVA; Fig. $4 A, B$, left, $C$ ), although this difference was not evident at higher stimulus intensities (Fig. $4 A, B$, right, $C$ ).

Because the above measurements of feedforward E/I ratios and nerve-evoked action potential discharge encompass both monosynaptic and polysynaptic inputs to developing spino-PB neurons, they do not allow for a straightforward comparison of the functional properties of direct muscle afferent versus cutaneous afferent synapses onto immature projection neurons. Therefore, subsequent experiments sought to identify the key characteristics of isolated monosynaptic EPSCs generated by the stimulation of sensory fibers traveling in the GS and sural nerves. Given the lack of convergent monosynaptic input to individual spino-PB neurons during early life (Fig. $2 B, C$ ), GS or sural nerve stimulation was applied to separate populations of immature spino-PB neurons in the following studies.

\section{Short-term plasticity at muscle and cutaneous afferent synapses onto developing projection neurons}

Although it is known that the probability of glutamate release $\left(\mathrm{P}_{\mathrm{r}}\right)$ at primary afferent synapses can be modulated by early sensory experience ( $\mathrm{Li}$ and Baccei, 2011), the degree to which $\mathrm{P}_{\mathrm{r}}$ depends on the peripheral target of the sensory neuron remains unclear. This issue was addressed by administering paired stimulation of the sural or GS nerves to evoke monosynaptic EPSCs in neonatal spino-PB neurons (Fig. 5A). Interestingly, the PPR was significantly lower following the stimulation of the GS nerve $(n=10)$ compared with the activation of the sural nerve $\left(n=17 ; F_{(1,91)}=\right.$ 24.27; $p<0.0001$; two-way ANOVA) at multiple interstimulus intervals ( $p<0.05$ at $75 \mathrm{~ms}$ interval; $p<0.01$ at $100 \mathrm{~ms}$; Bonferroni multiple-comparisons test; Fig. $5 B$ ). Because PPR is inversely related to $\mathrm{P}_{\mathrm{r}}$ (Thomson, 2000), these data point to a higher probability of glutamate release at muscle afferent synapses onto immature lamina I projection neurons compared with cutaneous inputs.

To further characterize short-term plasticity at distinct subtypes of afferent synapses onto ascending projection neurons, a train of electrical stimuli was applied to the GS or sural nerve at a range of frequencies ( 40 stimuli at $1-10 \mathrm{~Hz}$ ) and the mean plateau amplitude calculated (see Materials and Methods) as a measure of the EPSC amplitude at the end of the train compared with the first EPSC (Fig. 5C). Frequency-dependent STD was observed at both muscle $(n=7)$ and cutaneous $(n=14)$ afferent synapses onto neonatal spino-PB neurons $\left(F_{(3,76)}=42.13 ; p<0.0001\right.$;
A
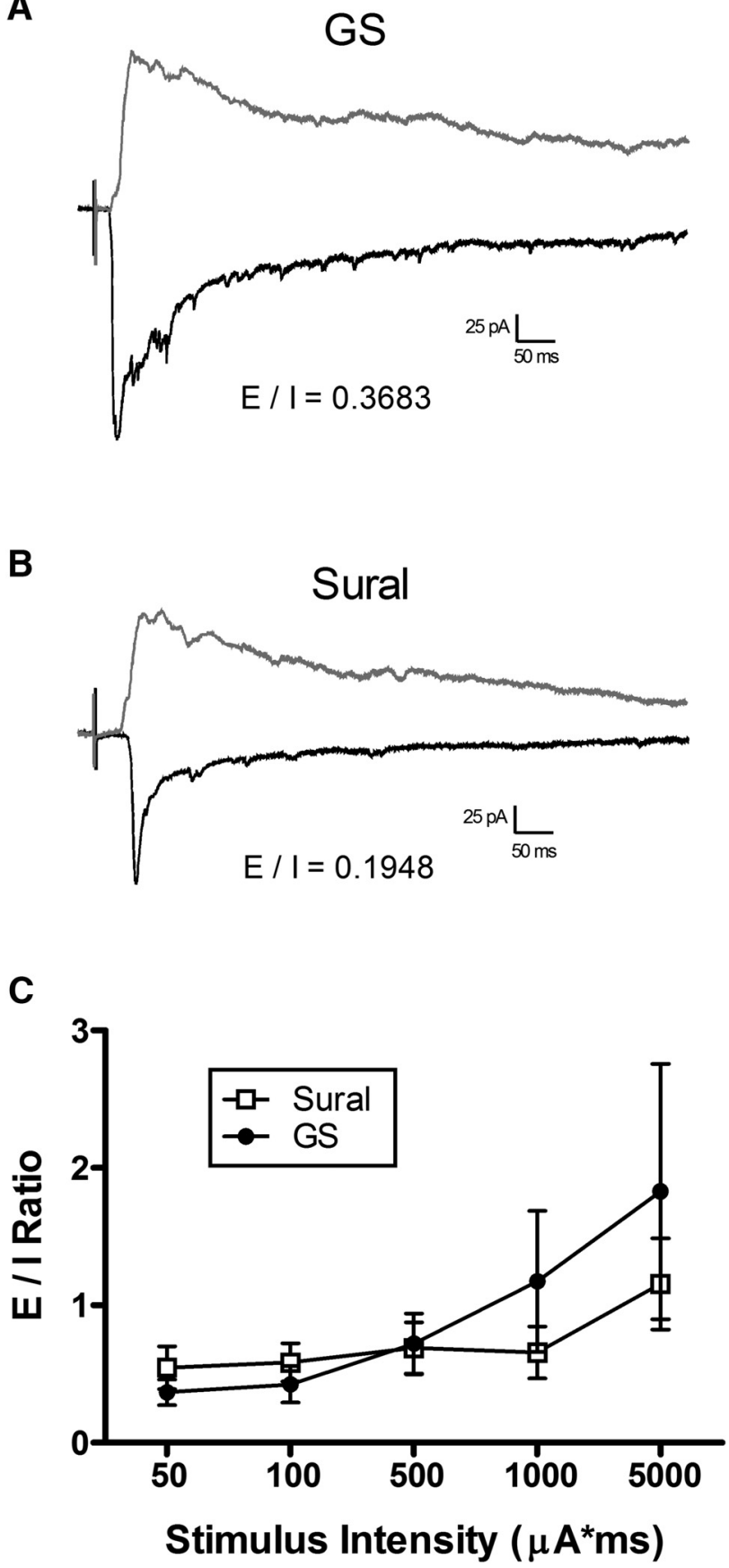

Figure 3. Ratio of "feedforward" excitation to inhibition onto ascending spinal projection neurons following cutaneous and muscle sensory input during early life. $A$, Example of EPSC (black) and IPSC (gray) evoked in an immature spino-PB neuron in response to the delivery of an electrical stimulus $(1 \mathrm{~mA}, 1 \mathrm{~ms})$ to the $\mathrm{GS}$ nerve. The areas under the postsynaptic currents were used to calculate the indicated E/I ratio. Illustrated traces were averaged from 5 consecutive EPSCS or IPSCS. B, Representative EPSC (black) and IPSC (gray) evoked in the same spino-PB neuron as shown in $\boldsymbol{A}$ following identical stimulation $(1 \mathrm{~mA}, 1 \mathrm{~ms}$ ) of the sural nerve. Traces represent the average of 5 consecutive EPSCs or IPSCS. C, In projection neurons that received convergent synaptic input from the sural and GS nerves, there were no significant differences in the $E / /$ ratio between cutaneous and muscle afferent inputs across the range of stimulus intensities examined ( $n=10 ; p=0.469$; two-way ANOVA).

two-way ANOVA; Fig. 5D). However, there was no significant difference in the magnitude of STD between GS versus sural nerve stimulation at any frequency examined $\left(F_{(1,76)}=2.17 ; p=\right.$ 0.145; two-way ANOVA; Fig. 5D). 
A

\section{Sural}
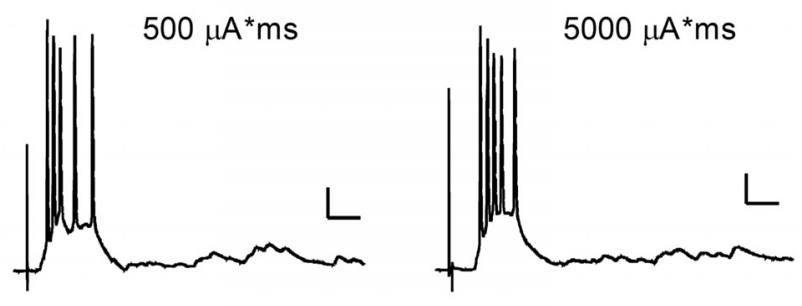

B

\section{GS}
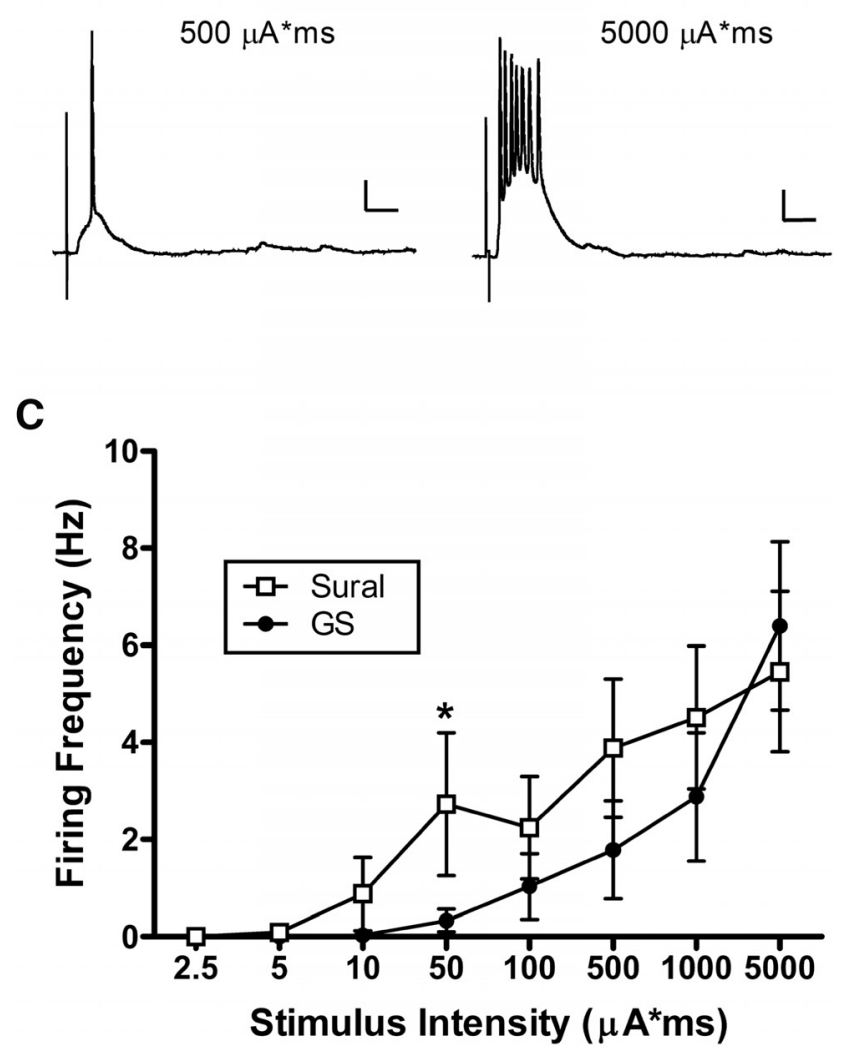

Figure 4. Convergent cutaneous and muscle afferent synapses drive the firing of immature lamina I projection neurons. $\boldsymbol{A}$, Examples of action potential discharge evoked in a neonatal spino-PB neuron in response to stimulation of the sural nerve at different intensities. Calibration: $10 \mathrm{mV}, 50 \mathrm{~ms}$. $\boldsymbol{B}$, Stimulation of the GS nerve also resulted in action potential firing in the same projection neuron as shown in $\boldsymbol{A}$. A lower firing frequency was observed in response to a 1 $\mathrm{mA}, 0.5 \mathrm{~ms}$ stimulus (left) compared with that following sural nerve stimulation ( $\boldsymbol{A}$, left), but a similar firing rate was seen with higher intensity stimulation ( $\boldsymbol{A}, \boldsymbol{B}$, right). Calibration: $10 \mathrm{mV}, 50$ ms. $C$, Sural nerve stimulation evoked a higher overall frequency of action potential discharge in projection neurons compared with activation of the GS nerve across the range of stimulus intensities examined ( $n=11 ; p=0.0025$; repeated-measures two-way ANOVA). ${ }^{*} p<0.05$ (Bonferonni post-test for multiple comparisons). The maximum postsynaptic firing rate was similar between the groups.

The ability of a given population of primary afferent synapses to recover from STD also has considerable functional implications for ascending nociceptive transmission to the brain. To compare the kinetics of recovery from STD at muscle and cutaneous afferent synapses onto immature spino-PB neurons, a train of 40 stimuli (at $10 \mathrm{~Hz}$ ) was delivered to the GS or sural nerve followed by a single test stimulus of the same intensity at an interval of $0.2-10 \mathrm{~s}$ (Fig. $5 E$ ). As expected, the degree of recovery from STD was highly dependent on the interval examined $\left(F_{(5,108)}=14.74 ; p<0.0001\right.$; two-way ANOVA; Fig. $\left.5 F\right)$. Meanwhile, there was no significant difference in recovery between muscle $(n=11)$ and cutaneous $(n=9)$ synapses at the intervals tested $\left(F_{(1,108)}=0.07 ; p=0.789\right.$; two-way ANOVA; Fig. $\left.5 F\right)$. Collectively, these results suggest that, despite a higher baseline probability of glutamate release at muscle afferent synapses onto lamina I projection neurons, the prolonged activation of sensory inputs to the spinal dorsal horn will lead to a short-term decrement in the efficacy of glutamatergic signaling that is comparable across different functional subtypes of primary afferent neurons.

\section{Enhanced t-LTP at muscle afferent synapses onto immature spino-PB neurons}

Although the activation of muscle afferents evokes greater LTP in the adult spinal dorsal horn compared with cutaneous inputs (Zhou et al., 2010), the prior reliance on extracellular field potentials makes it impossible to pinpoint the location of those synapses that are differentially potentiated by the stimulation protocol. To investigate whether muscle afferent synapses onto identified lamina I projection neurons are specifically capable of greater activity-dependent plasticity compared with cutaneous inputs, we first isolated monosynaptic EPSCs in neonatal spino-PB neurons following the electrical stimulation of the sural (Fig. $6 A$ ) or GS nerves. Next, postsynaptic action potentials were elicited via intracellular current injection at an interval $(\Delta \mathrm{t})$ of $10-50 \mathrm{~ms}$ after the onset of the afferent-evoked EPSP (i.e., $\Delta t=$ -10 to $-50 \mathrm{~ms}$ ). Similar pairing protocols have been previously demonstrated to evoke t-LTP at primary afferent synapses onto spino-PB neurons when dorsal root stimulation is used ( $\mathrm{Li}$ and Baccei, 2016). Indeed, these Pre $\rightarrow$ Post pairings could result in a persistent increase in the amplitude of EPSCs evoked by sural (Fig. $6 A, B$ ) as well as GS (data not shown) nerve stimulation.

However, the prevalence of t-LTP varied significantly between cutaneous and muscle afferent synapses onto immature projection neurons, as twice as many spino-PB neurons exhibited LTP in response to GS stimulation (22 of $26 ; \sim 85 \%$ ) compared with the use of sural nerve stimulation ( 11 of $26 ; \sim 42 \% ; p=0.007 ; \chi^{2}$ test; Fig. $6 C$ ). A minority of projection neurons displayed t-LTD following sural $(n=3)$ or GS $(n=1)$ nerve stimulation, with the remainder of cells showing no significant change in EPSC amplitude compared with the baseline (i.e., before administration of the Pre $\rightarrow$ Post pairing protocol). Across the chosen range of pairing intervals, a significantly greater magnitude of t-LTP was observed at muscle afferent synapses onto neonatal projection neurons compared with cutaneous inputs to the same population $\left(n=8\right.$ or 9 for each group/interval; $F_{(1,46)}=4.41 ; p=0.041$; two-way ANOVA; Fig. $6 D$ ). Interestingly, t-LTP was observed at each pairing protocol examined and there was no statistically significant effect of pairing interval on the magnitude of t-LTP $\left(F_{(2,46)}=0.33 ; p=0.721\right.$; two-way ANOVA; Fig. $\left.6 D\right)$. Although this points to a wider timing window for the induction of t-LTP in neonatal rat spino-PB neurons compared with their counterparts in the adult mouse ( $\mathrm{Li}$ and Baccei, 2016), it remains unclear whether this relates to the stage of postnatal development or to species-dependent differences in STDP at primary afferent synapses onto lamina I projection neurons.

\section{Conserved NMDAR properties at cutaneous and muscle afferent synapses onto immature spino-PB neurons}

STDP in many areas of the CNS requires the activation of NMDARs in the postsynaptic neuron (Magee and Johnston, 
A

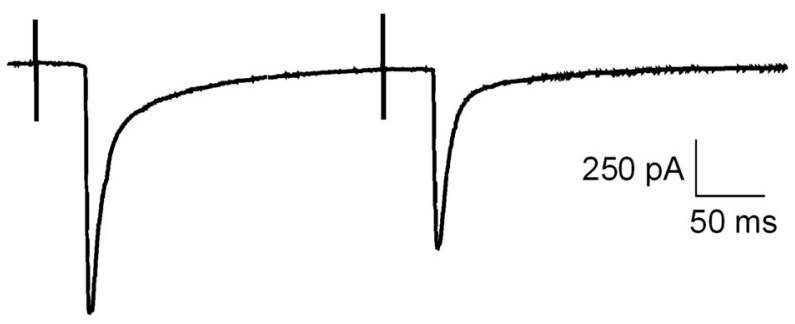

C
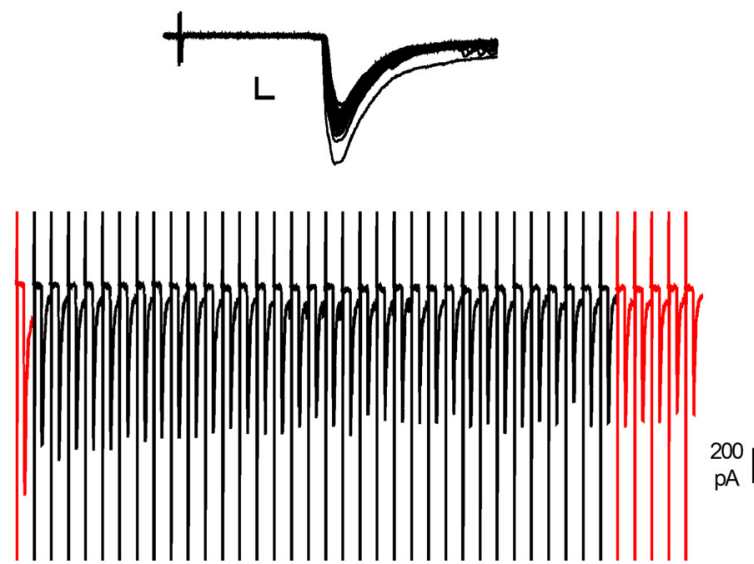

$\mathrm{x}=$ first $\mathrm{EPSC}$ amplitude

$y=$ mean of

last 5 EPSCs

E

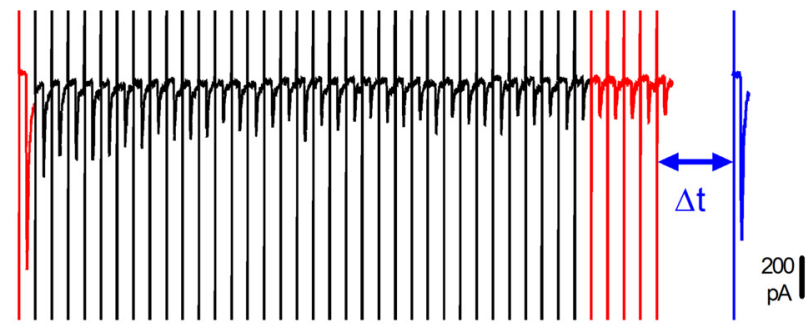

$\mathrm{x}=$ first EPSC amplitude

$y=$ mean of

last 5 EPSCs
B

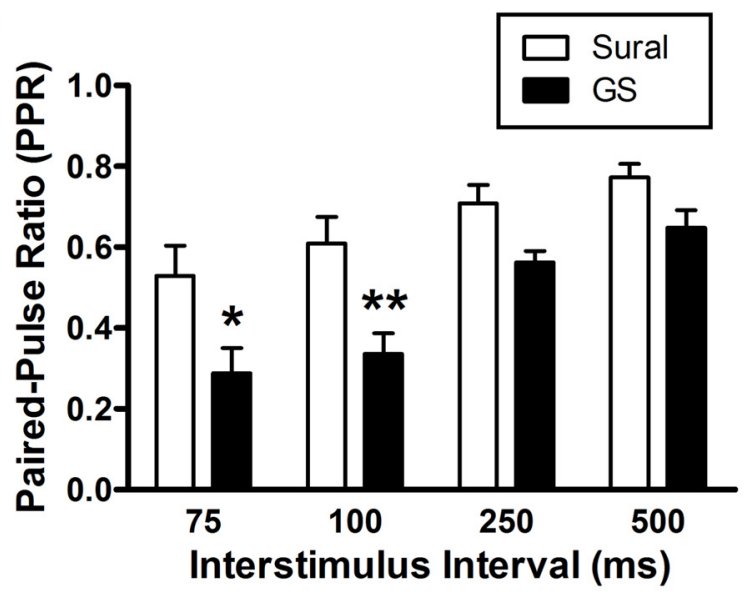

D

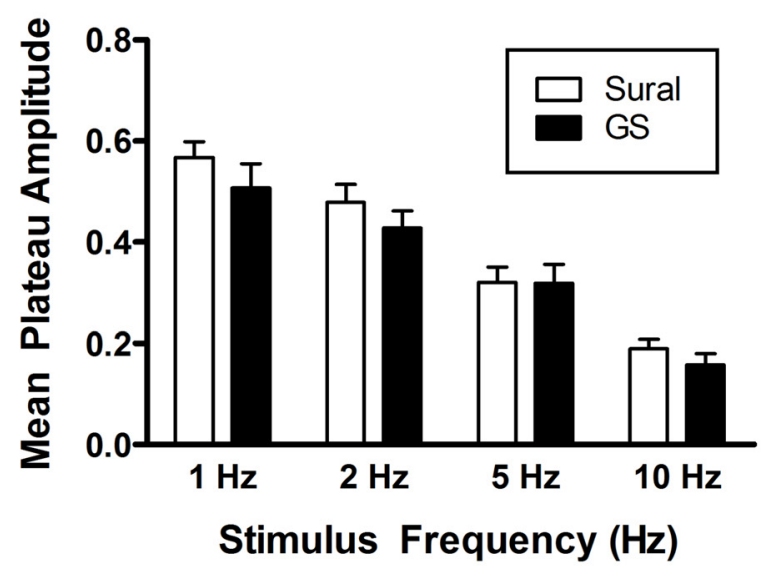

F

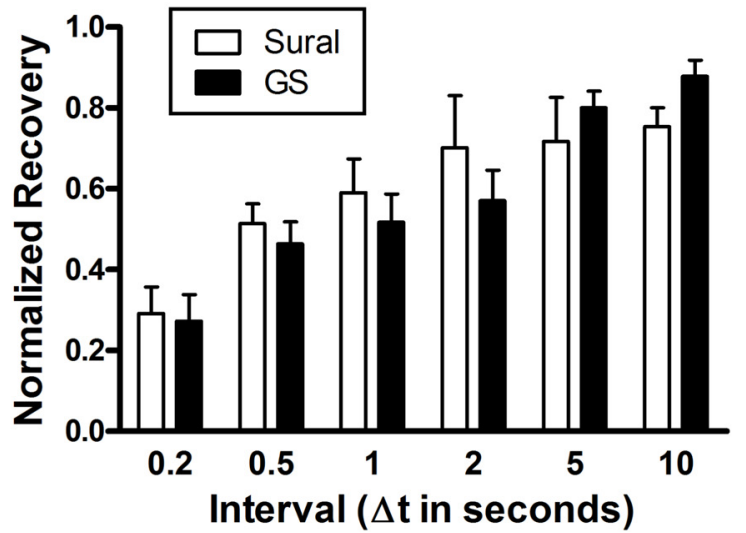

Figure 5. Elevated probability of glutamate release at muscle afferent synapses onto immature spinal projection neurons. $A$, Pairs of identical electrical stimuli were delivered to the sural or GS nerve at various interstimulus intervals to evoke monosynaptic EPSCs in spino-PB neurons, and the PPR calculated as mean EPSC2/mean EPSC1. B, The PPR was significantly lower for EPSCs evoked by GS stimulation $(n=10)$ compared with the activation of the sural nerve $\left(n=17 ; p<0.0001\right.$; two-way ANOVA). ${ }^{*} p<0.05$ at 75 ms interval (Bonferroni multiple-comparisons test). ${ }^{* *} p<0.01$ at $100 \mathrm{~ms}$ (Bonferroni multiple-comparisons test). This suggests a higher probability of glutamate release at muscle afferent synapses onto developing projection neurons. $C$, Top, Representative example of monosynaptic EPSCs evoked in a neonatal spino-PB neuron by a train of 40 stimuli delivered to the sural nerve at $2 \mathrm{~Hz}$. Calibration: $200 \mathrm{pA}, 5 \mathrm{~ms}$. C, Bottom, Concatenated trace of the same set of EPSCs illustrating how the mean plateau amplitude was calculated $(y / x)$. D. Cutaneous and muscle afferent synapses exhibited similar levels of frequency-dependent STD, as there were no significant differences in the calculated mean plateau amplitudes between sural and GS nerve stimulation ( $p=0.145$; two-way ANOVA). E, Concatenated trace showing EPSCS evoked by a stimulus train $(40$ stimuli at $10 \mathrm{~Hz}$ ) followed at a varying interval $(\Delta \mathrm{t})$ by a single test stimulus of the same intensity (blue). $\boldsymbol{F}$, The degree of recovery from STD, calculated as $(z-y) /(x-y)$, was similar between cutaneous and muscle afferent synapses at the intervals tested ( $p=0.789$; two-way ANOVA). 
A

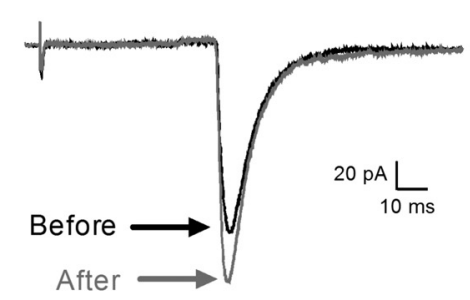

B

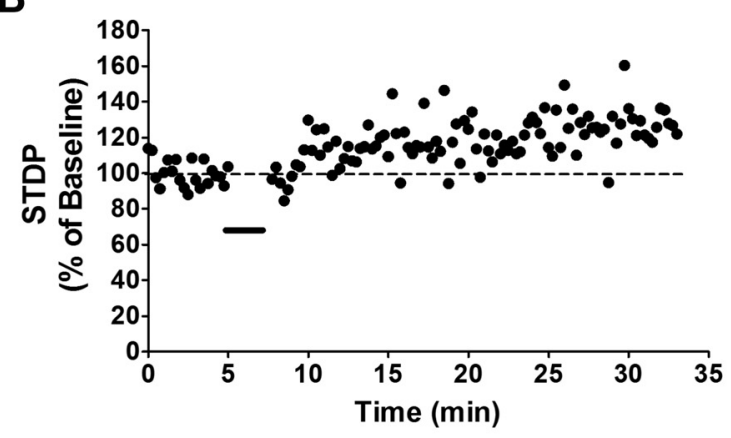

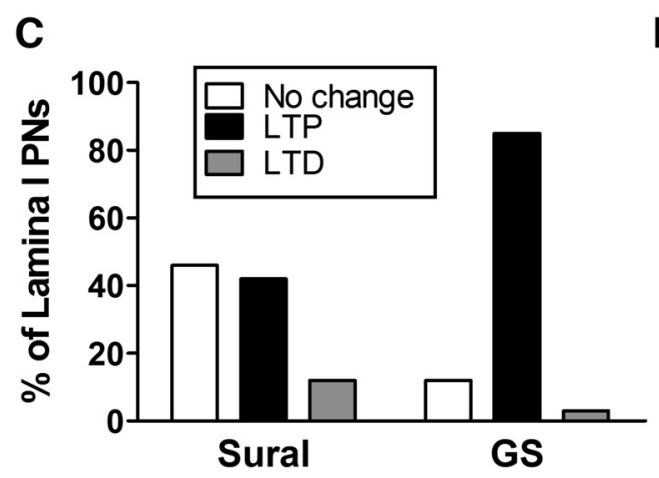

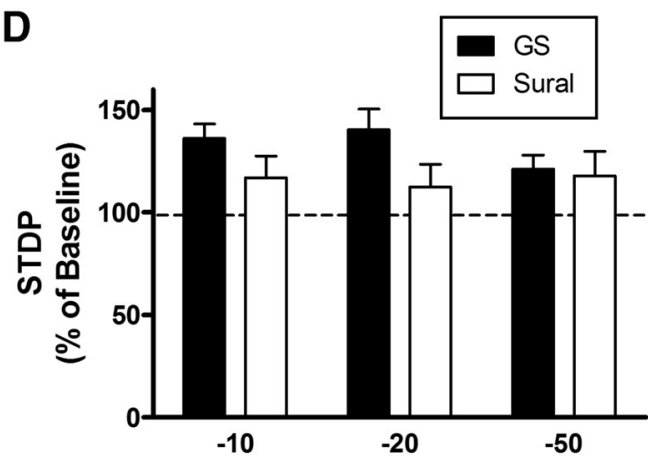

Pairing Interval ( $\Delta \mathrm{t}$; in $\mathrm{ms}$ )

Figure 6. Greater propensity for t-LTP at muscle afferent synapses onto neonatal spino-PB neurons. $\boldsymbol{A}$, Example of average monosynaptic EPSCs evoked by sural nerve stimulation either before (black) or after (gray) the administration of the t-LTP induction protocol (Pre $\rightarrow$ Post pairing at $\Delta t=-10 \mathrm{ms)}$ ). $\boldsymbol{B}$, EPSC amplitude versus time plot showing a slight potentiation of the EPSC following the t-LTP induction protocol (black bar). C, Percentage of spino-PB neurons exhibiting LTP, LTD, or no change in EPSC amplitude as a function of the peripheral nerve stimulated, demonstrating a higher prevalence of t-LTP at muscle afferent synapses ( $n=26$ in each group; $p=0.007 ; \chi^{2}$ test). $D$, The potentiation of EPSC amplitude was greater following paired Pre $\rightarrow$ Post stimulation of the GS nerve compared with the sural nerve at the intervals examined ( $n=8$ or 9 for each group/interval; $p=0.041 ;$ two-way ANOVA).

1997; Markram et al., 1997). To investigate the level of postsynaptic NMDAR expression at cutaneous and muscle afferent synapses onto immature spino-PB neurons, monosynaptic NMDAR-mediated EPSCs were evoked by sural or GS nerve stimulation from a holding potential of $50 \mathrm{mV}$ (Fig. 7A). Despite the greater t-LTP observed at muscle afferent synapses onto spino-PB neurons (Fig. 6), the overall amplitude of primary afferent-evoked NMDAR current (Fig. 7A) was similar when comparing stimulation of the GS $(n=14)$ and sural nerves $(n=$ $10 ; p=0.977$; Mann-Whitney test; Fig. 7B). NMDAR subunit composition, including the relative expression of NR2B-containing receptors, is also known to strongly influence the timing window governing STDP as well as its polarity (Gerkin et al., 2007; Kubota and Kitajima, 2008; Guo et al., 2012). Therefore, the enhanced t-LTP observed at muscle afferent synapses onto immature projection neurons compared with cutaneous inputs could potentially be explained by differences in the stoichiometry of postsynaptic NMDARs. However, fitting the decay phase of the NMDAR currents with a double exponential function revealed no differences in the fast $\left(\tau_{1}\right)$ or slow $\left(\tau_{2}\right)$ decay time constants of the EPSCs evoked by sural $(n=10)$ and GS $(n=9)$ nerve stimulation $\left(F_{(1,34)}=0.03 ; p=0.87\right.$; two-way ANOVA; Fig. $\left.7 C\right)$, suggesting a similar NMDAR subunit composition at cutaneous and muscle afferent synapses onto neonatal projection neurons. To specifically examine the relative contribution of the NR2B subunit to NMDAR-mediated EPSCs at the two types of synapses, we next characterized the sensitivity of NMDAR currents evoked by sural versus GS nerve stimulation to block by the selective NR2B antagonist Ro 25-6981 (Fig. 7A). The fraction of the
NMDAR EPSC blocked by Ro 25-6981 was similar between the sural $(n=8)$ and GS $(n=9)$ groups $(U=35 ; p=0.96$; MannWhitney test; Fig. 7D). These results further support the notion that NMDAR subunit composition is similar across cutaneous and muscle afferent synapses onto projection neurons during early life, although we cannot exclude the possibility that differences in NMDAR expression between the two types of synapses emerge at later stages of development. Collectively, the data strongly suggest that the enhanced t-LTP observed at immature muscle afferent synapses (Fig. 6) is unlikely to be explained by differences in NMDAR stoichiometry.

\section{Higher relative expression of $\mathrm{Ca}^{2+}$-permeable AMPARs at} muscle afferent synapses onto projection neurons facilitates synaptic LTP during early life

Meanwhile, our recent work has demonstrated that t-LTP at primary afferent synapses onto lamina I projection neurons can be facilitated by elevated levels of $\mathrm{Ca}^{2+}$-permeable AMPARs ( $\mathrm{Li}$ and Baccei, 2016). Therefore, we next explored the relative expression of $\mathrm{Ca}^{2+}$-permeable AMPARs at cutaneous and muscle afferent synapses onto projection neurons by determining the ability of the selective antagonist IEM 1460 to block monosynaptic EPSCs evoked by sural (Fig. 8A) or GS (Fig. 8B) nerve stimulation. EPSCs evoked by GS nerve stimulation were significantly more sensitive to IEM 1460 compared with those evoked by activating sural afferents (sural: $n=6$; GS: $n=9 ; U=3 ; p=0.0028$; Mann-Whitney test; Fig. $8 C$ ), thus pointing to a higher relative expression of $\mathrm{Ca}^{2+}$-permeable AMPARs at muscle afferent synapses onto immature spinal projection neurons. 
A

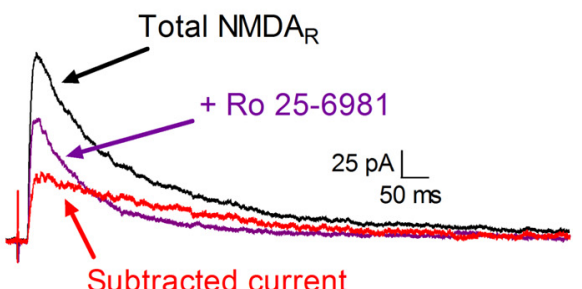

B

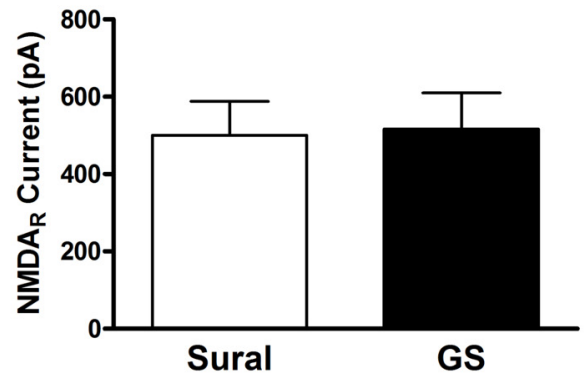

C

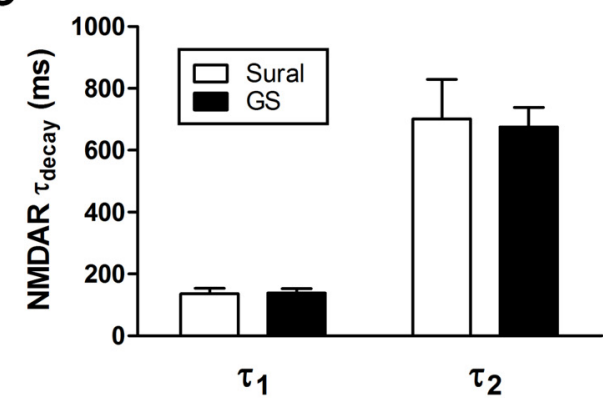

D

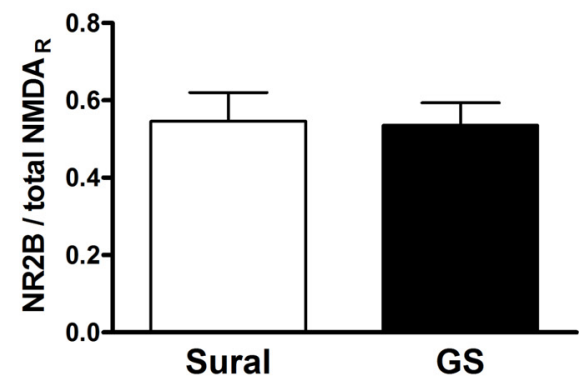

Figure 7. Similar postsynaptic NMDAR expression at cutaneous and muscle afferent synapses onto immature projection neurons. $\boldsymbol{A}$, Following the pharmacological isolation of monosynaptic NMDAR-mediated EPSCs (black) in neonatal spino-PB neurons, the selective antagonist of NR2B-containing NMDA receptors, Ro 25-6981, was bath applied (purple) and electronic subtraction used to isolate the NR2B component (red) of the overall NMDAR current. Illustrated traces were averaged from 5 consecutive EPSCs under a given experimental condition. $\boldsymbol{B}$, The mean amplitudes of the total NMDAR-mediated currents evoked by stimulation of the sural $(n=10)$ and $G S(n=14)$ nerves were similar $\left(p=0.977\right.$; Mann-Whitney test). $C$, There were no significant differences in the fast $\left(\tau_{1}\right)$ or slow $\left(\tau_{2}\right)$ decay time constants between NMDAR-mediated EPSCs evoked by sural $(n=$ $10)$ or GS $(n=9)$ nerve stimulation ( $p=0.871$; two-way ANOVA). $\boldsymbol{D}$, The fraction of total NMDAR current blocked by Ro 25-6981 was similar between the sural $(n=8)$ and GS $(n=$ 9) groups ( $p=0.962$; Mann-Whitney test), suggesting a similar NMDAR stoichiometry at cutaneous and muscle afferent synapses onto lamina I projection neurons during early life.
A

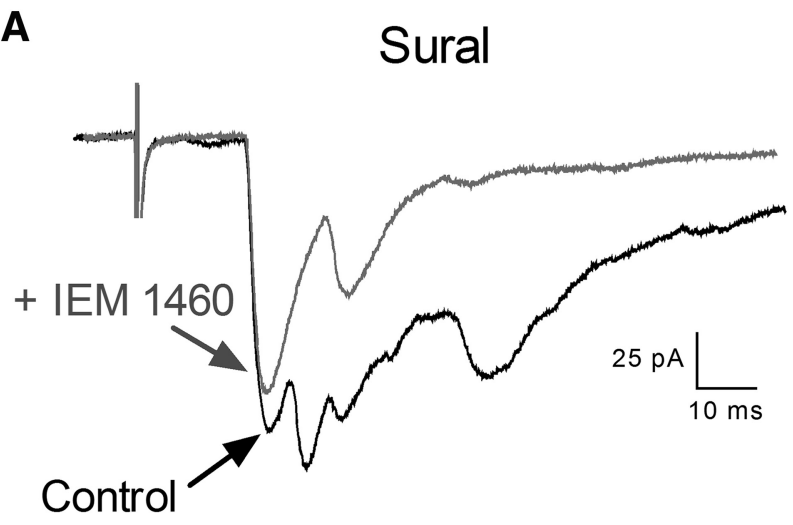

B

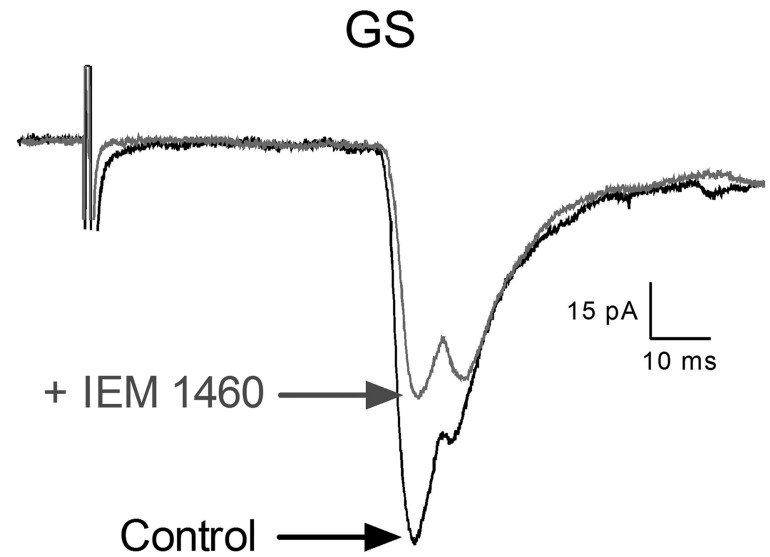

C

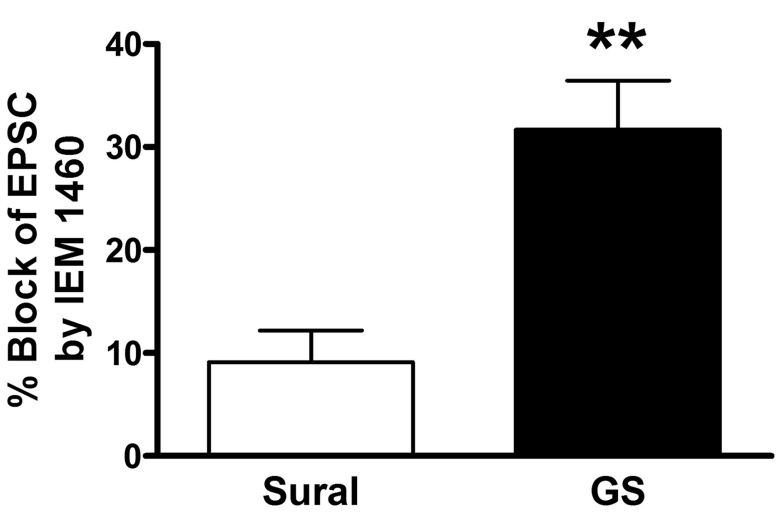

Figure 8. Elevated relative expression of $\mathrm{Ca}^{2+}$-permeable AMPARs at muscle afferent synapses onto ascending projection neurons. $A$, Example of monosynaptic EPSCs evoked in a neonatal spino-PB neuron by sural nerve stimulation before (black) and after (gray) the bath application of IEM $1460(10 \mu \mathrm{m})$, a selective antagonist of $\mathrm{Ca}^{2+}$-permeable AMPARs. $\boldsymbol{B}$, The amplitude of EPSCs evoked by GS nerve stimulation (in a different spino-PB neuron) was also reduced by IEM 1460. C, Monosynaptic EPSCS evoked by GS nerve stimulation $(n=9)$ were significantly more sensitive to block by IEM 1460 compared with those evoked by sural nerve stimulation $(n=6) .{ }^{* *} p=0.0028$ (Mann-Whitney test).

To elucidate the importance of $\mathrm{Ca}^{2+}$-permeable AMPARs for the induction of t-LTP at muscle afferent synapses, Pre $\rightarrow$ Post pairing protocols were applied at an interval of $10 \mathrm{~ms}$ (as described above; see Fig. 6) in the presence of IEM 1460. As expected, the amplitude of monosynaptic EPSCs evoked by stimulation of the GS nerve (Fig. $9 A$ ) was reduced by the bath application of IEM 1460 (Fig. 9B). However, the subsequent administration of the pairing protocol failed to significantly influence EPSC amplitude ( $n=4$; Fig. $9 B$, gray trace, $C)$, despite 
A

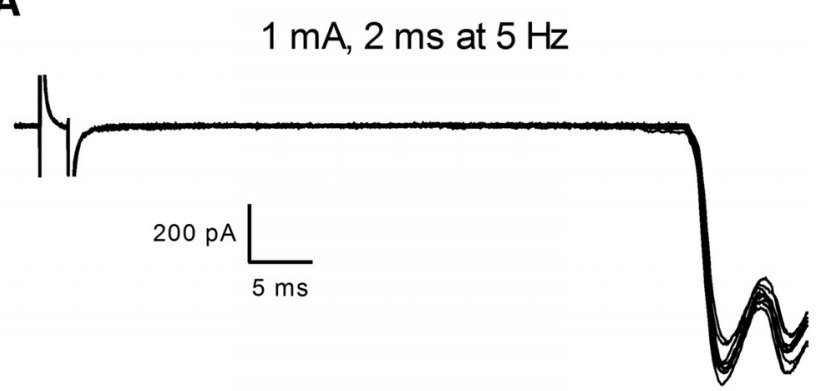

B
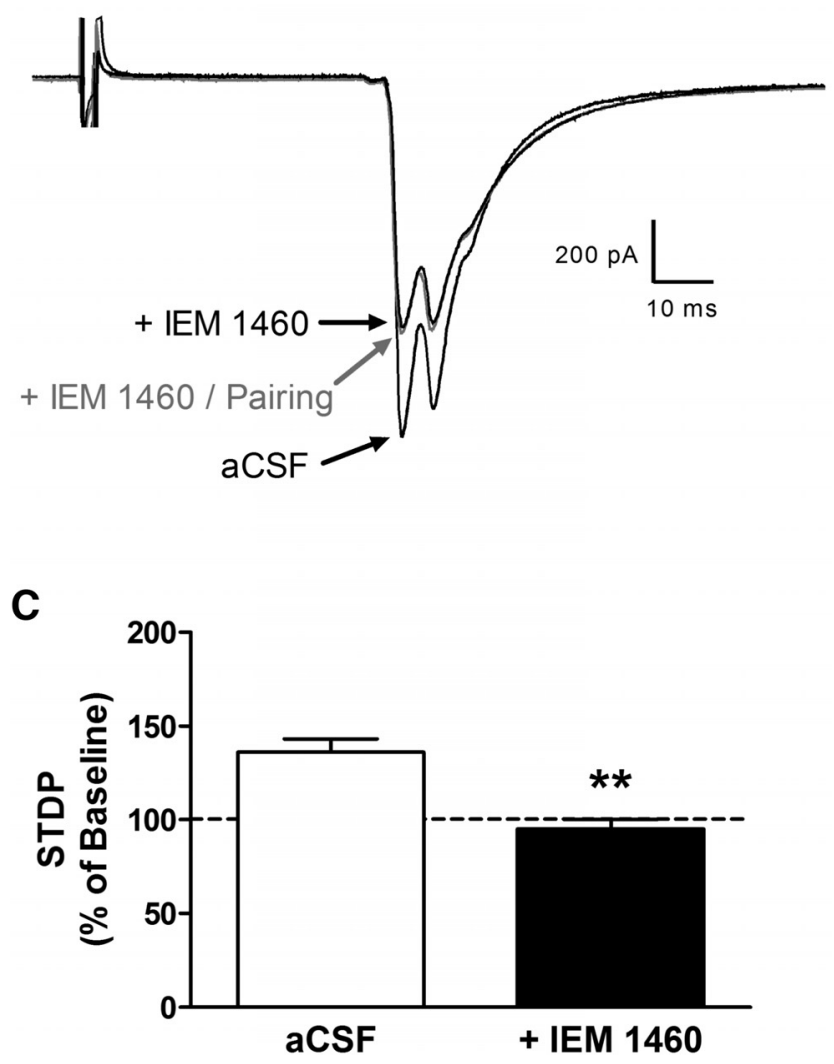

Figure 9. $\mathrm{Ca}^{2+}$-permeable AMPARs are required for the generation of t-LTP at muscle afferent synapses onto immature projection neurons. $A$, Example of monosynaptic EPSCs in a lamina I projection neuron following electrical stimulation of the GS nerve, identified by the ability to follow repetitive stimulation with a stable latency and absence of synaptic failures. $B$, Representative examples of EPSCS from the same projection neuron as in $\boldsymbol{A}$ before and after the application of the selective $\mathrm{Ca}^{2+}$-permeable AMPAR antagonist IEM $1460(10 \mu \mathrm{M})$. In the continued presence of IEM 1460, the subsequent administration of Pre $\rightarrow$ Post pairings at an interval of $10 \mathrm{~ms}$ ( $\Delta t=-10 \mathrm{~ms}$ ) failed to alter EPSC amplitude (gray). C, t-LTP at muscle afferent synapses was abolished by IEM $1460(n=4)$, whereas the same pairing interval $(\Delta t=-10 \mathrm{~ms})$ evokes clear t-LTP of GS inputs in the presence of aCSF $(n=9) .{ }^{* *} p=0.0028$ (Mann-Whitney test). Data at $\Delta t=-10 \mathrm{~ms}$ from Fig. 6 replotted here.

producing clear t-LTP under control conditions $(n=9 ; U=0$; $p=0.0028$; Mann-Whitney test; Fig. 9C). This suggests that the activation of $\mathrm{Ca}^{2+}$-permeable AMPARs is essential for evoking t-LTP at muscle afferent synapses onto developing projection neurons.

\section{Discussion}

Evidence points to important functional differences between the primary afferent neurons innervating skin versus muscle, includ- ing the timing of neurogenesis (Kitao et al., 2002), neurotrophin dependence (Hory-Lee et al., 1993), ion channel expression (Oyelese and Kocsis, 1996; Djouhri et al., 2003; Christianson et al., 2006), their ability to produce neurogenic extravasation (McMahon et al., 1984), and their response to peripheral injury (Tal et al., 1999; Liu et al., 2002). Surprisingly, the degree to which such phenotypic differences exist at their synapses onto secondorder nociceptive neurons within the spinal dorsal horn was unknown. The present study identifies, for the first time, key characteristics of cutaneous and muscle afferent synapses in the developing rodent $\mathrm{SDH}$, with a focus on the lamina I projection neurons that represent a major output of the spinal nociceptive circuit (Todd, 2010) and play an essential role in the generation of chronic pain (Mantyh et al., 1997; Nichols et al., 1999). The results indicate that, although many fundamental aspects of excitatory transmission are conserved across distinct classes of sensory neurons, cutaneous and muscle synapses exhibit significant differences in the probability of glutamate release, postsynaptic glutamate receptor expression and their susceptibility to activitydependent potentiation.

Our recent work has shown that unidentified primary afferent synapses onto ascending spinal projection neurons can undergo LTP if the presynaptic input precedes postsynaptic firing by a brief interval, while paired activity occurring in the reverse order fails to influence synaptic efficacy under normal conditions ( $\mathrm{Li}$ and Baccei, 2016). Using this model of t-LTP, the present study now demonstrates that muscle afferent synapses onto lamina I spino-PB neurons are significantly more likely to exhibit t-LTP in response to correlated Pre $\rightarrow$ Post pairings compared with cutaneous inputs to the same population (Fig. 6). Although further studies are needed to rigorously compare the precise timing windows governing the induction of t-LTP at cutaneous versus muscle afferent synapses onto immature projection neurons, the observed facilitation of LTP at muscle afferent synapses agrees with prior findings that the high-frequency stimulation of the GS nerve elicits more robust and persistent LTP of C fiber-evoked field potentials in the dorsal horn compared with sural nerve stimulation (Zhou et al., 2010; Zhang et al., 2016), which may be related to the differential expression of BDNF (Zhou et al., 2010).

The present data suggest that a higher relative expression of $\mathrm{Ca}^{2+}$-permeable AMPARs at muscle afferent synapses (Fig. 8) could also mediate the increased susceptibility to synaptic LTP (Hartmann et al., 2004; Youn et al., 2008; Li and Baccei, 2016). This greater relative level of $\mathrm{Ca}^{2+}$-permeable AMPARs seems unlikely to reflect an absence of the GluR2 subunit at muscle afferent synapses because the vast majority (96\%-99\%) of postsynaptic sites in the SDH contain GluR2 (Nagy et al., 2004; Antal et al., 2008). However, GluR1 expression varies significantly across postsynaptic sites, even those located in close proximity within an individual dorsal horn neuron (Antal et al., 2008). Therefore, although both muscle and cutaneous afferent synapses likely contain a mixture of $\mathrm{Ca}^{2+}$-impermeable and $\mathrm{Ca}^{2+}$-permeable AMPARs, it remains feasible that a higher ratio of GluR1:GluR2 expression exists at muscle afferent synapses compared with cutaneous inputs. Overall, a higher propensity for LTP at muscle synapses could contribute to the greater ability of GS afferents to evoke prolonged increases in the excitability of the spinal flexion reflex compared with sural afferents (Wall and Woolf, 1984). This is known to be related to their peripheral targets, as cross-anastomosing the sural and GS nerves leads to a switch whereby persistent reflex potentiation is seen following sural stimulation but limited potentiation is produced by GS stimulation (McMahon and Wall, 1989). 
Prior anatomical studies of the central projections of muscle afferents have yielded conflicting results regarding the extent to which these fibers terminate within lamina I of the spinal cord (Craig and Mense, 1983; Abrahams et al., 1984; Bakker et al., 1984; Abrahams and Swett, 1986; Ling et al., 2003). The current study clearly demonstrates that afferents traveling in the rat GS nerve establish monosynaptic connections onto spino-PB neurons during early life (Figs. $1 E ; 2 C$ ). In addition, the majority of sampled projection neurons received convergent synaptic input from the sural and GS nerves, which agrees with previous reports of an overlap in the distribution of their central terminals within lamina I (Panneton et al., 2005), although this convergence appears to be strictly polysynaptic in nature (Fig. 2). Somatic and visceral sensory afferents also send convergent excitatory inputs to individual dorsal horn neurons (Foreman et al., 1981; Cervero and Tattersall, 1987; Luz et al., 2015; Farrell et al., 2016), and the repetitive activation of one class of afferent can sensitize dorsal horn neurons to sensory input arising from another peripheral target (Cervero et al., 1992; Euchner-Wamser et al., 1993; Peles et al., 2004). Therefore, it seems likely that at least some projection neurons with dual cutaneous and muscle input also receive synaptic drive from visceral afferents, as reported for other spinal neurons (Pomeranz et al., 1968; Mørch et al., 2007), although the degree of convergence could vary according to the rostrocaudal location of the postsynaptic neuron (Mørch et al., 2007). Because the ability of a given population of synapses to modulate neuronal excitability can be strongly influenced by not only their density but also their location within the dendritic arbor (Rall and Rinzel, 1973; Rinzel and Rall, 1974), it will ultimately be important to determine the overall spatial distribution of cutaneous, muscle, and visceral afferent synapses onto ascending spinal projection neurons.

Low-threshold $A \beta$-fiber input to the spinal dorsal horn activates multiple populations of inhibitory interneurons that are essential for suppressing the activation of nociceptive pathways by innocuous mechanical stimuli (Torsney and MacDermott, 2006; Daniele and MacDermott, 2009; Lu et al., 2013; Duan et al., 2014; Petitjean et al., 2015). Cutaneous nerves, such as the sural nerve, contain a high proportion of low-threshold mechanoreceptive afferents (Lewin and McMahon, 1991a), which terminate in the dorsal horn (Li et al., 2011). Therefore, one potential explanation for the higher prevalence of musculoskeletal pain compared with pain arising from skin is that muscle afferents are more capable of driving the output of the spinal nociceptive circuit due to a higher ratio of "feedforward" synaptic excitation versus inhibition onto ascending projection neurons. However, the present data suggest that afferents in the sural and GS nerves evoke a similar E/I ratio at their synapses onto lamina I spino-PB neurons (Fig. 3). Indeed, greater action potential discharge was observed in response to stimulation of the sural nerve at lower intensities (Fig. 4), which may reflect the fact that most lowthreshold mechanoreceptive fibers in the GS nerve respond to muscle stretch (Lewin and McMahon, 1991b) and thus likely project to the ventral horn rather than dorsal laminae. Nonetheless, it should be noted that our analysis was restricted to a single population of lamina I neurons targeting the $\mathrm{PB}$, and it remains possible that muscle afferents display a higher E/I ratio compared with cutaneous afferents at their connections onto deeper projection neurons within lamina $\mathrm{V}$, which also receives extensive input from the GS nerve (Craig and Mense, 1983; Panneton et al., 2005; Lambertz et al., 2006). In addition, given the prior anatomical reports suggesting that the central terminals of muscle afferents may be distributed over a greater rostrocaudal length than cuta- neous afferents (Ling et al., 2003), one cannot exclude the possibility that GS stimulation recruits action potential firing across a larger number of spinal projection neurons compared with sural nerve stimulation. This issue could be addressed by the use of $\mathrm{Ca}^{2+}$-imaging approaches to measure overall population activity within lamina I projection neurons in the intact spinal cord (Drdla et al., 2009; Laffray et al., 2011) after sural or GS stimulation.

While the stimulation of the sural and GS nerves will not exclusively activate cutaneous and muscle primary afferents, as these nerves contain a mixture of sensory and motor fibers (Nakanishi and Norris, 1970), the discharge of motor efferent fibers in the nerves cannot retrogradely influence sensory processing in the dorsal horn (O'Donovan et al., 2010) given the absence of ventral roots in our recording preparation (Fig. 1A). However, it has yet to be determined whether the present findings can be generalized across other skin and muscle inputs to the SDH, including primary afferents traveling in the saphenous nerve, which is purely cutaneous (Lynn and Carpenter, 1982). Finally, the degree to which the functional differences in glutamatergic signaling between cutaneous and muscle afferents are maintained throughout life remains unclear, as synaptic circuits within the $\mathrm{SDH}$ are known to undergo significant reorganization during the early postnatal period (Keller et al., 2001; Baccei et al., 2003; Baccei and Fitzgerald, 2004; Cordero-Erausquin et al., 2005).

In conclusion, despite many similarities in the functional organization of cutaneous and muscle afferent synapses onto immature spinal projection neurons, a higher relative expression of $\mathrm{Ca}^{2+}$-permeable AMPARs elevates the susceptibility of muscle afferent synapses to activity-dependent potentiation, which may in turn facilitate the sensitization of central nociceptive circuits.

\section{References}

Abrahams VC, Swett JE (1986) The pattern of spinal and medullary projections from a cutaneous nerve and a muscle nerve of the forelimb of the cat: a study using the transganglionic transport of HRP. J Comp Neurol 246: 70-84. CrossRef Medline

Abrahams VC, Richmond FJ, Keane J (1984) Projections from C2 and C3 nerves supplying muscles and skin of the cat neck: a study using transganglionic transport of horseradish peroxidase. J Comp Neurol 230:142-154. CrossRef Medline

Antal M, Fukazawa Y, Eördögh M, Muszil D, Molnár E, Itakura M, Takahashi M, Shigemoto R (2008) Numbers, densities, and colocalization of AMPA- and NMDA-type glutamate receptors at individual synapses in the superficial spinal dorsal horn of rats. J Neurosci 28:9692-9701. CrossRef Medline

Baba H, Doubell TP, Moore KA, Woolf CJ (2000) Silent NMDA receptormediated synapses are developmentally regulated in the dorsal horn of the rat spinal cord. J Neurophysiol 83:955-962. Medline

Baccei ML, Fitzgerald M (2004) Development of GABAergic and glycinergic transmission in the neonatal rat dorsal horn. J Neurosci 24:4749-4757. CrossRef Medline

Baccei ML, Bardoni R, Fitzgerald M (2003) Development of nociceptive synaptic inputs to the neonatal rat dorsal horn: glutamate release by capsaicin and menthol. J Physiol 549:231-242. CrossRef Medline

Bakker DA, Richmond FJ, Abrahams VC (1984) Central projections from cat suboccipital muscles: a study using transganglionic transport of horseradish peroxidase. J Comp Neurol 228:409-421. CrossRef Medline

Bardoni R, Magherini PC, MacDermott AB (1998) NMDA EPSCs at glutamatergic synapses in the spinal cord dorsal horn of the postnatal rat. J Neurosci 18:6558-6567. Medline

Cervero F, Tattersall JE (1987) Somatic and visceral inputs to the thoracic spinal cord of the cat: marginal zone (lamina I) of the dorsal horn. J Physiol 388:383-395. CrossRef Medline

Cervero F, Laird JM, Pozo MA (1992) Selective changes of receptive field properties of spinal nociceptive neurones induced by noxious visceral stimulation in the cat. Pain 51:335-342. CrossRef Medline

Christianson JA, McIlwrath SL, Koerber HR, Davis BM (2006) Transient 
receptor potential vanilloid 1-immunopositive neurons in the mouse are more prevalent within colon afferents compared to skin and muscle afferents. Neuroscience 140:247-257. CrossRef Medline

Cordero-Erausquin M, Coull JA, Boudreau D, Rolland M, De Koninck Y (2005) Differential maturation of GABA action and anion reversal potential in spinal lamina I neurons: impact of chloride extrusion capacity. J Neurosci 25:9613-9623. CrossRef Medline

Craig AD, Mense S (1983) The distribution of afferent fibers from the gastrocnemius-soleus muscle in the dorsal horn of the cat, as revealed by the transport of horseradish peroxidase. Neurosci Lett 41:233-238. CrossRef Medline

Daniele CA, MacDermott AB (2009) Low-threshold primary afferent drive onto GABAergic interneurons in the superficial dorsal horn of the mouse. J Neurosci 29:686-695. CrossRef Medline

Djouhri L, Newton R, Levinson SR, Berry CM, Carruthers B, Lawson SN (2003) Sensory and electrophysiological properties of guinea-pig sensory neurones expressing Nav $1.7(\mathrm{PN} 1) \mathrm{Na}^{+}$channel alpha subunit protein. J Physiol 546:565-576. CrossRef Medline

Drdla R, Gassner M, Gingl E, Sandkühler J (2009) Induction of synaptic long-term potentiation after opioid withdrawal. Science 325:207-210. CrossRef Medline

Duan B, Cheng L, Bourane S, Britz O, Padilla C, Garcia-Campmany L, Krashes M, Knowlton W, Velasquez T, Ren X, Ross SE, Lowell BB, Wang Y, Goulding M, Ma Q (2014) Identification of spinal circuits transmitting and gating mechanical pain. Cell 159:1417-1432. CrossRef Medline

Euchner-Wamser I, Sengupta JN, Gebhart GF, Meller ST (1993) Characterization of responses of T2-T4 spinal cord neurons to esophageal distension in the rat. J Neurophysiol 69:868-883. Medline

Farrell KE, Rank MM, Keely S, Brichta AM, Graham BA, Callister RJ (2016) In vivo characterization of colorectal and cutaneous inputs to lumbosacral dorsal horn neurons in the mouse spinal cord. Neuroscience 316:1325. CrossRef Medline

Foreman RD, Hancock MB, Willis WD (1981) Responses of spinothalamic tract cells in the thoracic spinal cord of the monkey to cutaneous and visceral inputs. Pain 11:149-162. CrossRef Medline

Gerkin RC, Lau PM, Nauen DW, Wang YT, Bi GQ (2007) Modular competition driven by NMDA receptor subtypes in spike-timing-dependent plasticity. J Neurophysiol 97:2851-2862. CrossRef Medline

Guo Y, Huang S, de Pasquale R, McGehrin K, Lee HK, Zhao K, Kirkwood A (2012) Dark exposure extends the integration window for spike-timingdependent plasticity. J Neurosci 32:15027-15035. CrossRef Medline

Hartmann B, Ahmadi S, Heppenstall PA, Lewin GR, Schott C, Borchardt T, Seeburg PH, Zeilhofer HU, Sprengel R, Kuner R (2004) The AMPA receptor subunits GluR-A and GluR-B reciprocally modulate spinal synaptic plasticity and inflammatory pain. Neuron 44:637-650. CrossRef Medline

Hoorneman EM (1985) Stereotaxic operation in the neonatal rat: a novel and simple procedure. J Neurosci Methods 14:109-116. CrossRef Medline

Hory-Lee F, Russell M, Lindsay RM, Frank E (1993) Neurotrophin 3 supports the survival of developing muscle sensory neurons in culture. Proc Natl Acad Sci U S A 90:2613-2617. CrossRef Medline

Hunfeld JA, Perquin CW, Duivenvoorden HJ, Hazebroek-Kampschreur AA, Passchier J, van Suijlekom-Smit LW, van der Wouden JC (2001) Chronic pain and its impact on quality of life in adolescents and their families. J Pediatr Psychol 26:145-153. CrossRef Medline

IJpma FF, Nicolai JP, Meek MF (2006) Sural nerve donor-site morbidity: thirty-four years of follow-up. Ann Plast Surg 57:391-395. CrossRef Medline

Ikeda H, Stark J, Fischer H, Wagner M, Drdla R, Jäger T, Sandkühler J (2006) Synaptic amplifier of inflammatory pain in the spinal dorsal horn. Science 312:1659-1662. CrossRef Medline

Jastrowski Mano KE, Khan KA, Ladwig RJ, Weisman SJ (2011) The impact of pediatric chronic pain on parents' health-related quality of life and family functioning: reliability and validity of the PedsQL 4.0 Family Impact Module. J Pediatr Psychol 36:517-527. CrossRef Medline

Jensen TS, Finnerup NB (2014) Allodynia and hyperalgesia in neuropathic pain: clinical manifestations and mechanisms. Lancet Neurol 13:924935. CrossRef Medline

Keller AF, Coull JA, Chery N, Poisbeau P, De Koninck Y (2001) Regionspecific developmental specialization of GABA-glycine cosynapses in laminas I-II of the rat spinal dorsal horn. J Neurosci 21:7871-7880. Medline

King S, Chambers CT, Huguet A, MacNevin RC, McGrath PJ, Parker L, MacDonald AJ (2011) The epidemiology of chronic pain in children and adolescents revisited: a systematic review. Pain 152:2729-2738. CrossRef Medline

Kitao Y, Robertson B, Kudo M, Grant G (2002) Proliferation patterns of dorsal root ganglion neurons of cutaneous, muscle and visceral nerves in the rat. J Neurocytol 31:765-776. CrossRef Medline

Kubota S, Kitajima T (2008) A model for synaptic development regulated by NMDA receptor subunit expression. J Comput Neurosci 24:1-20. CrossRef Medline

Laffray S, Pagès S, Dufour H, De Koninck P, De Koninck Y, Côté D (2011) Adaptive movement compensation for in vivo imaging of fast cellular dynamics within a moving tissue. PLoS One 6:e19928. CrossRef Medline Lambertz D, Hoheisel U, Mense S (2006) Distribution of synaptic field potentials induced by TTX-resistant skin and muscle afferents in rat spinal segments L4 and L5. Neurosci Lett 409:14-18. CrossRef Medline

Latremoliere A, Woolf CJ (2009) Central sensitization: a generator of pain hypersensitivity by central neural plasticity. J Pain 10:895-926. CrossRef Medline

Lewin GR, McMahon SB (1991a) Physiological properties of primary sensory neurons appropriately and inappropriately innervating skin in the adult rat. J Neurophysiol 66:1205-1217. Medline

Lewin GR, McMahon SB (1991b) Physiological properties of primary sensory neurons appropriately and inappropriately innervating skeletal muscle in adult rats. J Neurophysiol 66:1218-1231. Medline

Li J, Baccei ML (2011) Neonatal tissue damage facilitates nociceptive synaptic input to the developing superficial dorsal horn via NGF-dependent mechanisms. Pain 152:1846-1855. CrossRef Medline

Li J, Baccei ML (2016) Neonatal tissue damage promotes spike timingdependent synaptic long-term potentiation in adult spinal projection neurons. J Neurosci 36:5405-5416. CrossRef Medline

Li J, Kritzer E, Craig PE, Baccei ML (2015) Aberrant synaptic integration in adult lamina I projection neurons following neonatal tissue damage. J Neurosci 35:2438-2451. CrossRef Medline

Li L, Rutlin M, Abraira VE, Cassidy C, Kus L, Gong S, Jankowski MP, Luo W, Heintz N, Koerber HR, Woodbury CJ, Ginty DD (2011) The functional organization of cutaneous low-threshold mechanosensory neurons. Cell 147:1615-1627. CrossRef Medline

Li P, Zhuo M (1998) Silent glutamatergic synapses and nociception in mammalian spinal cord. Nature 393:695-698. CrossRef Medline

Ling LJ, Honda T, Shimada Y, Ozaki N, Shiraishi Y, Sugiura Y (2003) Central projection of unmyelinated (C) primary afferent fibers from gastrocnemius muscle in the guinea pig. J Comp Neurol 461:140-150. CrossRef Medline

Liu CN, Devor M, Waxman SG, Kocsis JD (2002) Subthreshold oscillations induced by spinal nerve injury in dissociated muscle and cutaneous afferents of mouse DRG. J Neurophysiol 87:2009-2017. CrossRef Medline

Lu Y, Dong H, Gao Y, Gong Y, Ren Y, Gu N, Zhou S, Xia N, Sun YY, Ji RR, Xiong L (2013) A feed-forward spinal cord glycinergic neural circuit gates mechanical allodynia. J Clin Invest 123:4050-4062. CrossRef Medline

Luz LL, Fernandes EC, Sivado M, Kokai E, Szucs P, Safronov BV (2015) Monosynaptic convergence of somatic and visceral C-fiber afferents on projection and local circuit neurons in lamina I: a substrate for referred pain. Pain 156:2042-2051. CrossRef Medline

Lynn B, Carpenter SE (1982) Primary afferent units from the hairy skin of the rat hind limb. Brain Res 238:29-43. CrossRef Medline

Magee JC, Johnston D (1997) A synaptically controlled, associative signal for Hebbian plasticity in hippocampal neurons. Science 275:209-213. CrossRef Medline

Mantyh PW, Rogers SD, Honore P, Allen BJ, Ghilardi JR, Li J, Daughters RS, Lappi DA, Wiley RG, Simone DA (1997) Inhibition of hyperalgesia by ablation of lamina I spinal neurons expressing the substance P receptor. Science 278:275-279. CrossRef Medline

Markram H, Lübke J, Frotscher M, Sakmann B (1997) Regulation of synaptic efficacy by coincidence of postsynaptic APs and EPSPs. Science 275: 213-215. CrossRef Medline

McMahon SB, Wall PD (1985) The distribution and central termination of single cutaneous and muscle unmyelinated fibres in rat spinal cord. Brain Res 359:39-48. CrossRef Medline 
McMahon SB, Wall PD (1989) Changes in spinal cord reflexes after crossanastomosis of cutaneous and muscle nerves in the adult rat. Nature 342:272-274. CrossRef Medline

McMahon SB, Sykova E, Wall PD, Woolf CJ, Gibson SJ (1984) Neurogenic extravasation and substance $P$ levels are low in muscle as compared to skin the rat hindlimb. Neurosci Lett 52:235-240. CrossRef Medline

Mense S, Craig AD Jr (1988) Spinal and supraspinal terminations of primary afferent fibers from the gastrocnemius-soleus muscle in the cat. Neuroscience 26:1023-1035. CrossRef Medline

Merlijn VP, Hunfeld JA, van der Wouden JC, Hazebroek-Kampschreur AA, Koes BW, Passchier J (2003) Psychosocial factors associated with chronic pain in adolescents. Pain 101:33-43. CrossRef Medline

Miloro M, Stoner JA (2005) Subjective outcomes following sural nerve harvest. J Oral Maxillofac Surg 63:1150-1154. CrossRef Medline

Mørch CD, Hu JW, Arendt-Nielsen L, Sessle BJ (2007) Convergence of cutaneous, musculoskeletal, dural and visceral afferents onto nociceptive neurons in the first cervical dorsal horn. Eur J Neurosci 26:142-154. CrossRef Medline

Nagy GG, Al-Ayyan M, Andrew D, Fukaya M, Watanabe M, Todd AJ (2004) Widespread expression of the AMPA receptor GluR2 subunit at glutamatergic synapses in the rat spinal cord and phosphorylation of GluR1 in response to noxious stimulation revealed with an antigen-unmasking method. J Neurosci 24:5766-5777. CrossRef Medline

Nakanishi T, Norris FH Jr (1970) Motor fibers in rat sural nerve. Exp Neurol 26:433-435. CrossRef Medline

Nichols ML, Allen BJ, Rogers SD, Ghilardi JR, Honore P, Luger NM, Finke MP, Li J, Lappi DA, Simone DA, Mantyh PW (1999) Transmission of chronic nociception by spinal neurons expressing the substance P receptor. Science 286:1558-1561. CrossRef Medline

O’Donovan MJ, Bonnot A, Mentis GZ, Chub N, Pujala A, Alvarez FJ (2010) Mechanisms of excitation of spinal networks by stimulation of the ventral roots. Ann N Y Acad Sci 1198:63-71. CrossRef Medline

Oyelese AA, Kocsis JD (1996) GABAA-receptor-mediated conductance and action potential waveform in cutaneous and muscle afferent neurons of the adult rat: differential expression and response to nerve injury. J Neurophysiol 76:2383-2392. Medline

Öztop DB, Taşdelen Bİ, PoyrazoğLu HG, Ozsoy S, Yilmaz R, Şahın N, Per H, Bozkurt S (2016) Assessment of psychopathology and quality of life in children and adolescents with migraine. J Child Neurol 31:837-842. CrossRef Medline

Panneton WM, Gan Q, Juric R (2005) The central termination of sensory fibers from nerves to the gastrocnemius muscle of the rat. Neuroscience 134:175-187. CrossRef Medline

Peles S, Miranda A, Shaker R, Sengupta JN (2004) Acute nociceptive somatic stimulus sensitizes neurones in the spinal cord to colonic distension in the rat. J Physiol 560:291-302. CrossRef Medline

Perquin CW, Hazebroek-Kampschreur AA, Hunfeld JA, Bohnen AM, van Suijlekom-Smit LW, Passchier J, van der Wouden JC (2000) Pain in children and adolescents: a common experience. Pain 87:51-58. CrossRef Medline

Petitjean H, Pawlowski SA, Fraine SL, Sharif B, Hamad D, Fatima T, Berg J, Brown CM, Jan LY, Ribeiro-da-Silva A, Braz JM, Basbaum AI, SharifNaeini R (2015) Dorsal horn parvalbumin neurons are gate-keepers of touch-evoked pain after nerve injury. Cell Rep 13:1246-1257. CrossRef Medline
Pomeranz B, Wall PD, Weber WV (1968) Cord cells responding to fine myelinated afferents from viscera, muscle and skin. J Physiol 199:511532. CrossRef Medline

Prescott SA, De Koninck Y (2002) Four cell types with distinctive membrane properties and morphologies in lamina I of the spinal dorsal horn of the adult rat. J Physiol 539:817-836. CrossRef Medline

Rabbitts JA, Holley AL, Groenewald CB, Palermo TM (2016) Association between widespread pain scores and functional impairment and healthrelated quality of life in clinical samples of children. J Pain 17:678-684. CrossRef Medline

Rall W, Rinzel J (1973) Branch input resistance and steady attenuation for input to one branch of a dendritic neuron model. Biophys J 13:648-687. CrossRef Medline

Rinzel J, Rall W (1974) Transient response in a dendritic neuron model for current injected at one branch. Biophys J 14:759-790. CrossRef Medline

Safronov BV, Pinto V, Derkach VA (2007) High-resolution single-cell imaging for functional studies in the whole brain and spinal cord and thick tissue blocks using light-emitting diode illumination. J Neurosci Methods 164:292-298. CrossRef Medline

Sandkühler J, Gruber-Schoffnegger D (2012) Hyperalgesia by synaptic long-term potentiation (LTP): an update. Curr Opin Pharmacol 12:18 27. CrossRef Medline

Stanford EA, Chambers CT, Biesanz JC, Chen E (2008) The frequency, trajectories and predictors of adolescent recurrent pain: a population-based approach. Pain 138:11-21. CrossRef Medline

Szucs P, Pinto V, Safronov BV (2009) Advanced technique of infrared LED imaging of unstained cells and intracellular structures in isolated spinal cord, brainstem, ganglia and cerebellum. J Neurosci Methods 177:369380. CrossRef Medline

Tal M, Wall PD, Devor M (1999) Myelinated afferent fiber types that become spontaneously active and mechanosensitive following nerve transection in the rat. Brain Res 824:218-223. CrossRef Medline

Thomson AM (2000) Facilitation, augmentation and potentiation at central synapses. Trends Neurosci 23:305-312. CrossRef Medline

Todd AJ (2010) Neuronal circuitry for pain processing in the dorsal horn. Nat Rev Neurosci 11:823-836. CrossRef Medline

Torsney C, MacDermott AB (2006) Disinhibition opens the gate to pathological pain signaling in superficial neurokinin 1 receptor-expressing neurons in rat spinal cord. J Neurosci 26:1833-1843. CrossRef Medline

Wall PD, Woolf CJ (1984) Muscle but not cutaneous C-afferent input produces prolonged increases in the excitability of the flexion reflex in the rat. J Physiol 356:443-458. CrossRef Medline

Woolf CJ (2011) Central sensitization: implications for the diagnosis and treatment of pain. Pain 152 [Suppl 3]:S2-S15.

Youn DH, Royle G, Kolaj M, Vissel B, Randić M (2008) Enhanced LTP of primary afferent neurotransmission in AMPA receptor GluR2-deficient mice. Pain 136:158-167. CrossRef Medline

Zhang J, Hoheisel U, Klein T, Magerl W, Mense S, Treede RD (2016) Highfrequency modulation of rat spinal field potentials: effects of slowly conducting muscle vs skin afferents. J Neurophysiol 115:692-700. CrossRef Medline

Zhou LJ, Ren WJ, Zhong Y, Yang T, Wei XH, Xin WJ, Liu CC, Zhou LH, Li YY, Liu XG (2010) Limited BDNF contributes to the failure of injury to skin afferents to produce a neuropathic pain condition. Pain 148:148157. CrossRef Medline 